\title{
Structural derivatization strategies of natural phenols by semi-synthesis and total-synthesis
}

\author{
Ding Lin Li, $^{1 *+}$, Senze Jiang ${ }^{1,2+}$, Ailian Zhang ${ }^{1,2}$, Tong W $\mathbf{u}^{1,2}$, Yongchang Qian ${ }^{1,2}$ and Qingsong Shao ${ }^{1,2^{*}}$
}

\begin{abstract}
Structural derivatization of natural products has been a continuing and irreplaceable source of novel drug leads. Natural phenols are a broad category of natural products with wide pharmacological activity and have offered plenty of clinical drugs. However, the structural complexity and wide variety of natural phenols leads to the difficulty of structural derivatization. Skeleton analysis indicated most types of natural phenols can be structured by the combination and extension of three common fragments containing phenol, phenylpropanoid and benzoyl. Based on these fragments, the derivatization strategies of natural phenols were unified and comprehensively analyzed in this review. In addition to classical methods, advanced strategies with high selectivity, efficiency and practicality were emphasized. Total synthesis strategies of typical fragments such as stilbenes, chalcones and flavonoids were also covered and analyzed as the supplementary for supporting the diversity-oriented derivatization of natural phenols.
\end{abstract}

Keywords: Natural phenols, Structural derivatization, Common fragments, Total synthesis

\section{Introduction}

Natural phenols are a large class of natural products ranging from simple phenol, such as salicylic acid, to complex polyphenol, such as tannins [1]. They widely exist in plants, microbes and foods as diverse forms containing glycosides, ethers, ester and free phenol. Numerous studies have strongly supported the prevention and therapeutic effects of natural phenols against various diseases including cancers [2], cardiovascular [3], neurodegeneration $[4,5]$, and infection. [6] Dietary phenols, such as tea polyphenols, are also regarded as good antioxidative, anti-inflammatory and neuroprotective agents [7]. Several natural phenols have already been applied in clinic and food industry. Cannabidiol, a nonpsychotropic phytocannabinoid of Cannabis sativa, has been used as analgesic, antiepileptic and anxiolytic drug [8]. Capsaicin, the famous flavouring agent, was utilized as antiphlogistic in clinic [9]. Natural flavonoids such as

\footnotetext{
*Correspondence: linding@zafu.edu.cn; sqszjfc@126.com

†Ding Lin and Senze Jiang contributed equally to this work

${ }^{1}$ State Key Laboratory of Subtropical Silviculture, Zhejiang A \& F

University, Hangzhou 311300, China

Full list of author information is available at the end of the article
}

eupatilin and genistein were also reported as adjuvant drugs for the treatment of tumors and inflammation [10, 11]. However, most natural phenols were less than satisfactory in efficacy or side effect.

Structural derivatization is the fundamental way to solve the defects of natural phenols and improve the clinical applicability, and has already been a main approach for drug development [12]. Lots of clinical drugs have been developed by the derivatization of natural phenols (Fig. 1). Aspirin, a nonsteroidal antiinflammatory drug, and mycophenolate mofetil, an immunosuppressor, were structurally derived from natural phenolic acid [13]. The choleretic drug metochalcone and anti-ulcer agent sofalcone were developed through modifying natural chalcone [14]. Synthetic anthracycline antibiotics such as amrubicin and valrubicin were also originated from natural phenols and have been applied in the treatment of tumor [15]. In addition, as it's getting harder to discover novel types of natural phenols on accessible land, it's of growing importance to take full advantage of existing natural phenols and extend the structural types by diversity-oriented derivatization.

\section{Springer}

(C) The Author(s) 2022. Open Access This article is licensed under a Creative Commons Attribution 4.0 International License, which permits use, sharing, adaptation, distribution and reproduction in any medium or format, as long as you give appropriate credit to the original author(s) and the source, provide a link to the Creative Commons licence, and indicate if changes were made. The images or other third party material in this article are included in the article's Creative Commons licence, unless indicated otherwise in a credit line to the material. If material is not included in the article's Creative Commons licence and your intended use is not permitted by statutory regulation or exceeds the permitted use, you will need to obtain permission directly from the copyright holder. To view a copy of this licence, visit http://creativecommons.org/licenses/by/4.0/. 


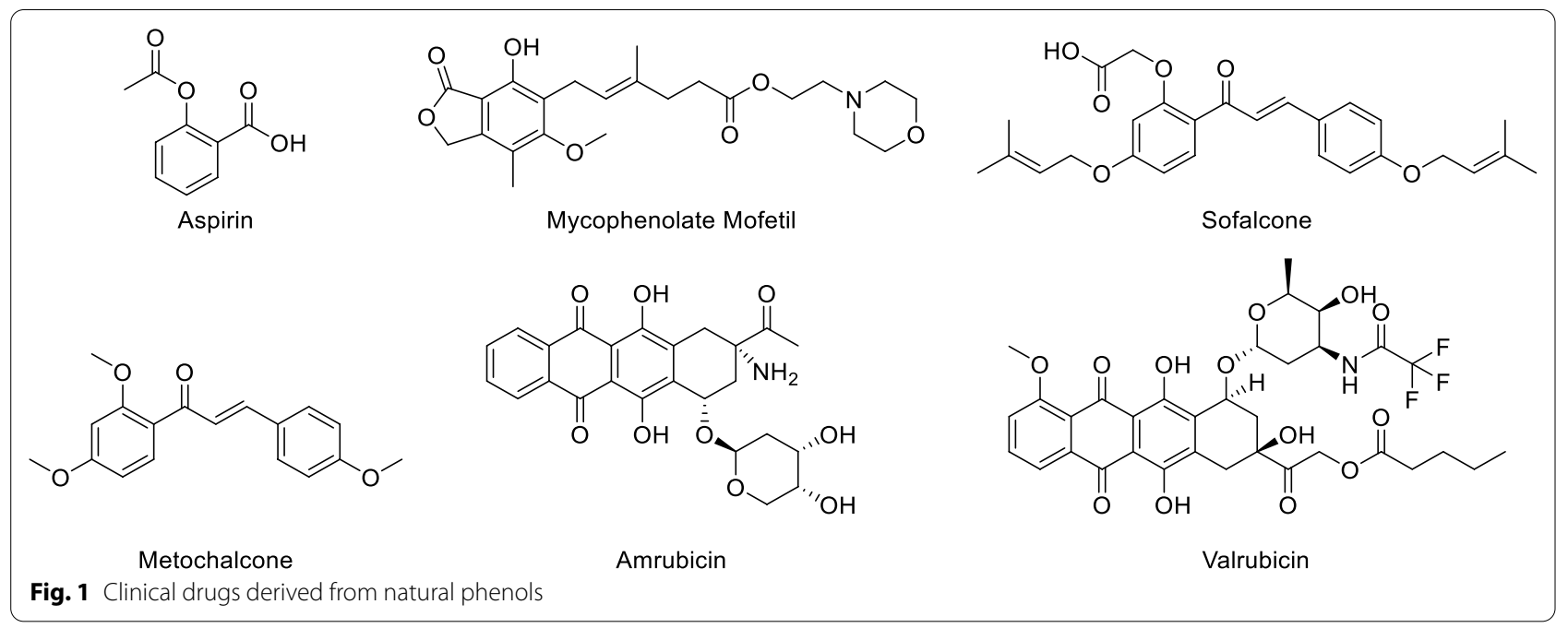

Currently there are various derivatization concepts at present such as scaffold hopping [16], structural simplification [17], removal of unnecessary chiral centers [18] and combinatorial chemistry [19], but it's still hard to formulate derivatization schemes for natural phenols as chemical synthetic feasibility is the precondition. Fortunately, due to some genetic relation of earth's organism, no matter how complex the structures are, natural phenols always consist of common fragments (Fig. 1). Through analyzing the derivatization strategies of common fragments, derivatization schemes for most natural phenols can be easily formulated. Moreover, natural phenols often have multi-reactive sites, multi-chiral centers, complex three-dimensional structures, poor stability and few sources, which set more special requirements for synthetic methods and conditions. The present review not only cover classical derivatization methods, but also advanced strategies with high selectivity, high efficiency and mild condition. For further improving the diversity of derivatization, total synthesis strategies of several representative natural phenols fragments were also discussed, as they could break the limitation of scaffold and source.

\section{Structural derivatization strategies of natural phenols by semi-synthesis}

\subsection{Chemical classification and common fragments of natural phenols}

Natural phenols were known as a group of natural compounds characterized by at least one phenyl rings and one or more hydroxyl substituents. Common structure types of natural phenols were listed in Fig. 2, ranging from single phenyl compounds such as phenylpropanoids to complicated polyphenols. The big families of lignans and flavonoids were involved. In this review, not only phenols but simple phenolic ethers such as methyl and ethyl phenolic ethers were also included, as they widely exist as the derivatives of natural phenols and shared the same structural modification strategies with natural phenols.

Due to the great variety of natural phenols, it's unpractical to separately analyze the derivatization strategies for every type of natural phenols. Based on characteristic structures of chemical reactions, structural skeletons of different types of natural phenols were dissected. Three fragments containing phenol, phenylpropanoid and benzoyl were found to be the basic common fragments (Fig. 3). Most types of natural phenols can be structured from the combination and extension of the three common fragments, based on which the derivatization strategies can be unified. For instance, chalcone could be structurally divided into phenol and benzoyl. The derivatization strategies of phenol and benzoyl fragments could also be applied for chalcone. Therefore, the three fragments were regarded as the minimal characteristic fragments and chosen as the template for systematically analyzing the structural derivatization strategies.

\subsection{Derivatization strategies of phenol fragments}

2.2.1 Classical derivatization strategies of phenol fragments

As the basic structure of natural phenols, phenol fragments can be derivatized by modifying the phenolic hydroxyl or introducing specific groups onto the phenolic ring in various classical ways, which were summarized and presented in Scheme 1. Amongst them, electrophilic substitutions of phenolic hydroxyl were the most classical and usual strategies for the derivatization of natural phenols, mainly including acylation, alkylation and phosphorylation [20] (Scheme 1A-a,b,c), which were always applied in designing prodrug to improve the bioavailability or reduce side effect, such 


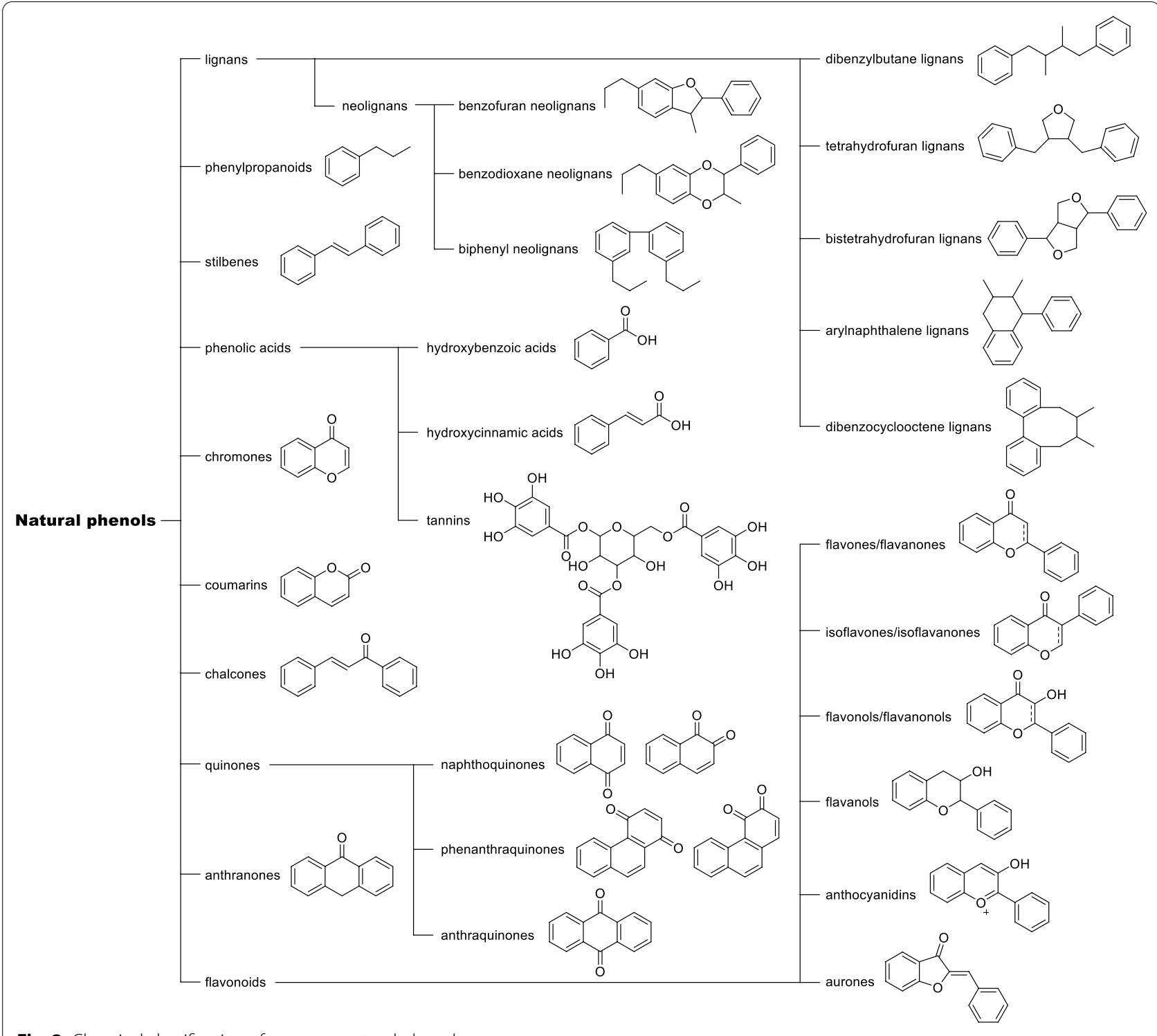

Fig. 2 Chemical classification of common natural phenols

as aspirin acylated from salicylic acid for reducing the stimulation on stomach [21], and the glycoside of resveratrol which exhibited quiet low toxicity on zebra fish ombryos (Fig. 3) [22]. Introducing specific groups will also improve the bioactivities by regulating lipidwater partition coefficient or the interaction between compound and biological target. For instance, replacing hydroxyl of resveratrol by bromoethyl and thienylcarbonyl obviously increase the cytotoxicity against $\mathrm{KB}$ cells and the anti-thrombin activity respectively (Fig. 4). Similarly, natural phenols can be converted to corresponding sulphonate, but it's seldom applied in derivatization of natural phenols due to the potential genotoxicity.
Compared to electrophilic substitutions, nucleophilic substitutions of phenolic hydroxyl were less applied in the derivatization of natural phenols which require extreme conditions to break $\mathrm{C}-\mathrm{O}$ bond due to $\mathrm{p}-\pi$ conjugation, unless there are electron-withdrawing groups on the phenolic ring. Some special approaches enabled to be the condition of nucleophilic substitutions more smoothly and made it applicable for the derivatization of natural phenols. For example, direct ammonolysis of phenolic hydroxyl demand very high temperature which is too dangerous for natural phenols, except natural naphthols which can be ammoniated by Bucherer reaction [23]. Introducing appropriate leaving group such as tosylate (Ts) [24] and triflate (Tf) [25] will reduce the 


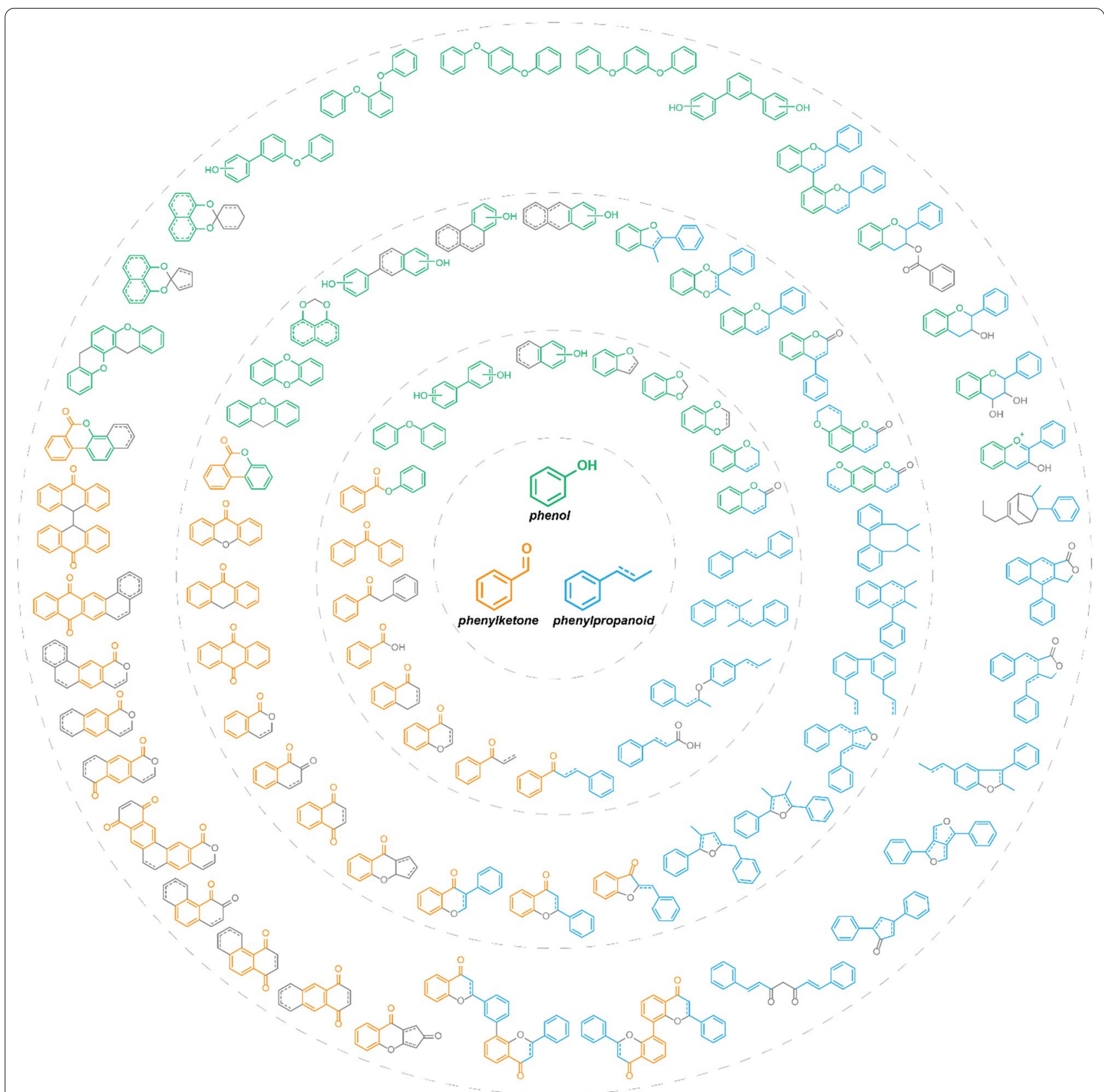

Fig. 3 Common fragments of natural phenols

difficulty of cleavage of $\mathrm{C}-\mathrm{O}$ bond, which always need the participation of metal catalysts (Scheme 1A-f, g, h). In recent years, a metal-free strategy with moderate condition was developed in which arylamine was synthesized by the rearrangement of aryloxy propylamine [26-29] (Scheme 1A-d, e). From the halide intermediate of natural phenols, various groups including cyano, carboxyl and aminoacyl can be introduced through a series of transformations (Scheme 1A-j, k), which have been applied in the derivatization of chalcones [30]. Preparation of Grignard reagent from the halide intermediate was a common strategy to obtain diversiform derivatives (Scheme 1A-l). However, it's not so applicable for complex polyphenols as it requires sufficient protection of active groups including phenolic hydroxyls. Furthermore, cross-coupling of arylhalide or aryltriflate with organoboron or organometal was also a potential strategy to introduce alkyl or aryl with a great diversity [31, 32] (Scheme 1A-m). 


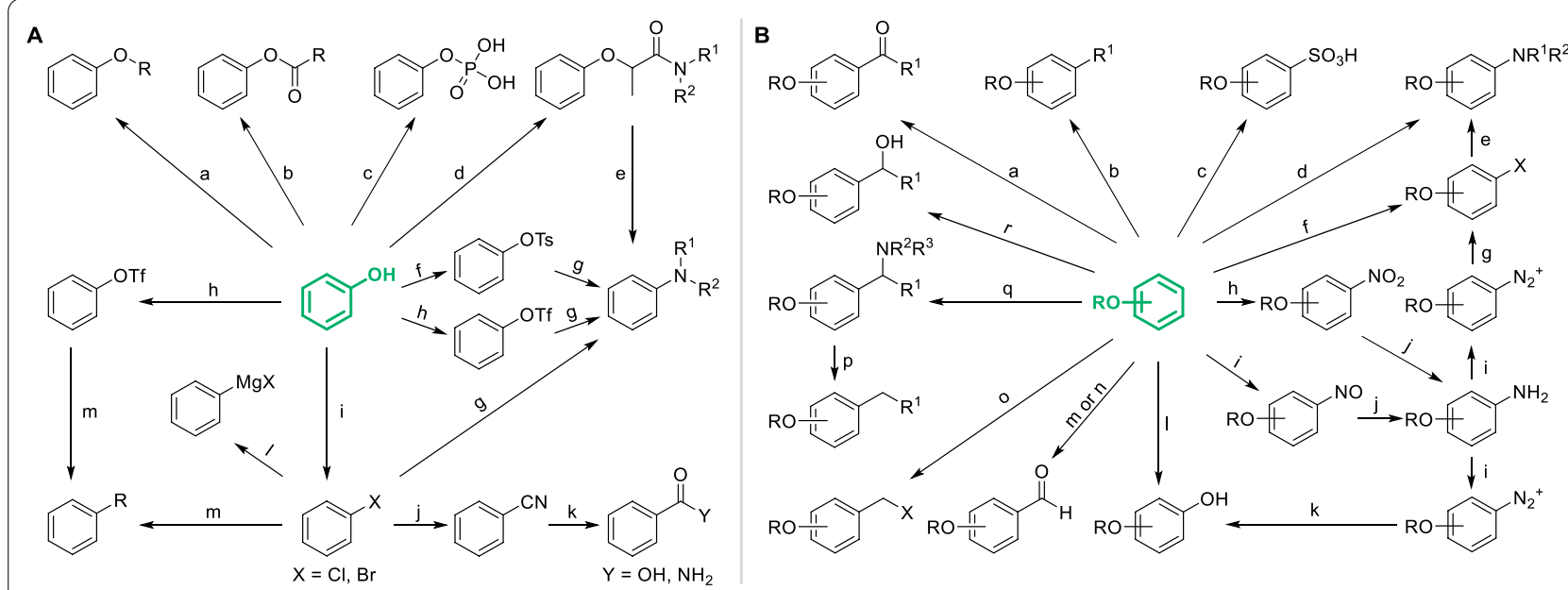

Scheme 1 Classical derivatization strategies of phenol fragments. A Derivatization of phenolic hydroxyl. Common conditions: a $\mathrm{ROH}_{1} \mathrm{RX}_{1} \mathrm{R}_{2} \mathrm{SO}_{4}$ or $\mathrm{R}_{2} \mathrm{CO}_{3} \mathbf{b}(\mathrm{RCO})_{2} \mathrm{O}$ or $\mathrm{RCOCl} \mathbf{c} \mathrm{POCl}_{3} \mathbf{d} \mathrm{CH}_{3} \mathrm{CH}(\mathrm{Br}) \mathrm{CONR}^{1} \mathrm{R}^{2}$ e base $\mathbf{f} \mathrm{TsCl} \mathbf{g} \mathrm{HNR}^{1} \mathrm{R}^{2}$, catalyst $\mathbf{h} \mathrm{TfO}_{2}$ or TfCll $\mathbf{i} \mathrm{PX}_{3}$. $\mathrm{PX}_{5}$ or POX 3 j cyanide $\mathbf{k} \mathrm{H}_{2} \mathrm{O} \mathbf{I} \mathrm{Mg}$, Et $\mathrm{P}_{2} \mathrm{O}$ $\mathbf{m} \mathrm{R}-\mathrm{M}, \mathrm{M}=\mathrm{B}(\mathrm{OH})_{2}$, $\mathrm{SnBu}_{3}$, etc.; $\mathbf{B}$ Introduction of various groups onto phenolic ring. Common conditions: $\mathbf{a} \mathrm{R}^{1} \mathrm{COX} / \mathrm{acid}$ catalyst $\mathbf{b} \mathrm{R}^{1} \mathrm{X} / \mathrm{acid}$ catalyst $\mathbf{c} \mathrm{H}_{2} \mathrm{SO}_{4} \mathbf{d} \mathrm{HNR}^{1} \mathrm{R}^{2}$ /oxidant/catalyst e $\mathrm{HNR}^{1} \mathrm{R}^{2} \mathbf{f}$ halogenating reagents $\mathbf{g} \mathrm{CuX} \mathbf{h} \mathrm{HNO}_{3}$ or t-BuONO $\mathbf{i ~ N a N O} \mathrm{Na}_{2} / \mathbf{j}$ various reductants $\mathbf{k} \mathrm{H}_{2} \mathrm{O} \mathbf{I}$ ) IBX, 2) $\mathrm{NaS}_{2} \mathrm{O}_{4} \mathbf{m} \mathrm{CHCl}_{3} / \mathrm{NaOH} \mathbf{n} \mathrm{DMF} / \mathrm{POCl}_{3}$ o $\mathrm{HX} / \mathrm{HCHO} /$ acid catalyst $\mathbf{p} \mathrm{Pd} / \mathrm{C}, \mathrm{H}_{2} \mathbf{q} \mathrm{R}^{1} \mathrm{CHO} / \mathrm{HNR}^{2} \mathrm{R}^{3} \mathbf{r} \mathrm{RCHO} /$ base

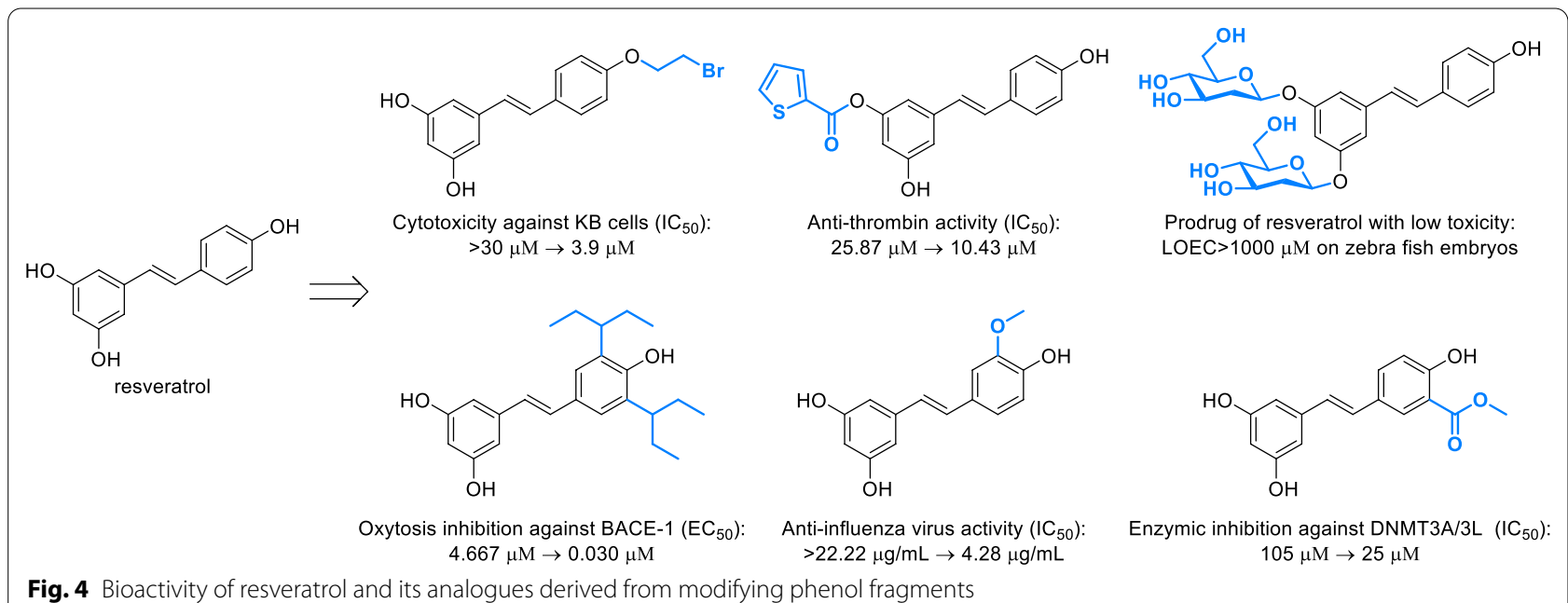

Introducing specific groups onto the phenolic ring may improve the bioactivity of natural phenols. Taking resveratrol for instance, the oxytosis inhibition against $\beta$-secretase, anti-influenza virus activity and enzymic inhibition against DNA-methyltransferase 3A/3L increased significantly after introducing certain groups onto the phenolic ring (Fig. 3). As an electronicrich aromatic ring, not only classical organic reactions including Friedel-Crafts alkylation (Scheme 1B-a), acylation (Scheme 1B-b), sulfonation (Scheme 1B-c), nitration (Scheme 1B-h), halogenation (Scheme 1B-f) and haloalkylation (Scheme 1B-o), but those reactions hardly occurring on aromatic ring such as Reimer-Tiemann reaction (Scheme 1B-m), Vilsmeier-Haack reaction (Scheme 1B-n), Mannich reaction (Scheme 1B-q) and nitrosation (Scheme 1B-i) could also smoothly proceed on phenolic rings, which improve the diversity of derivatization. Similarly to Mannich reaction, natural phenols can be hydroxyalkylated or halomethylated with aldehyde and corresponding reagents (Scheme 1B-o, r). As applied in the derivatization of natural anthraquinones [33], three kinds of alkylated derivatives can be easily converted to each other to obtain a great diversity of molecules. Secondary amine can be directly introduced by various oxidative cross-dehydrogenative coupling reactions or mediately introduced via arylhalide intermediate 
(a) Complete acylation and partial hydrolysis

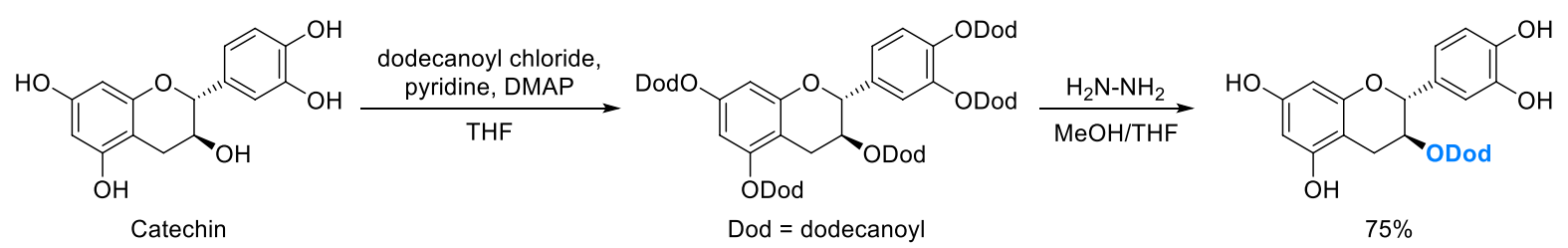

(b) Selective acylation between alcoholic and phenolic hydroxyl
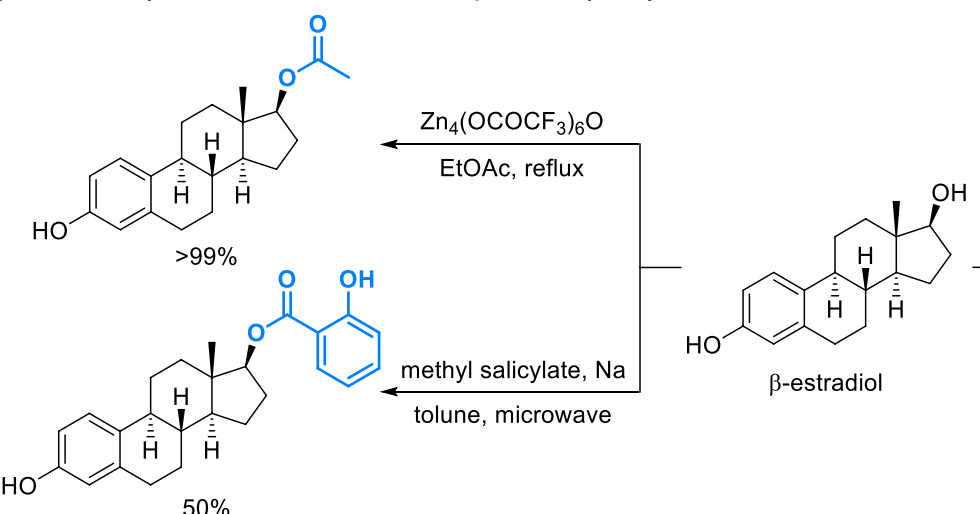

Scheme 2 Selective acylation between phenolic and alcoholic hydroxyls

(Scheme 1B-d,e). Various structures such as hydroxyl and halogen could be further derived from amino through diazotization [34, 35] (Scheme 1B-i, k). The hydroxylation of natural phenols can also be directly activated by 2-Iodylbenzoic acid (IBX) [36], which will selectively generate ortho-diphenols (Scheme 1B-k). Nevertheless, it's worth noting that IBX also induces the oxidative demethylation of phenolic ether and the dehydrogenation of acrylophenone, which have been observed in the derivatization of flavonoids [37]. Enzymatic activation was also an available approach for the transformation of phenols to diphenols as similar to biological metabolic processes [38]. Through combining different strategies, more kinds of groups can be introduced onto natural phenols.

\subsubsection{Selective derivatization strategies of phenol fragments} Influenced by complex structure of natural phenols which always contain multi-hydroxyls and rings, classical derivatization strategies probably caused multiple kinds of potential products. In recent years, some selective derivatization strategies of phenol fragments have been applied. As natural phenols always contain both phenolic and alcoholic hydroxyls, it's necessary to distinguish between two kinds of hydroxyls. One feasible strategy was combination of complete acylation with partial hydrolysis, as alcoholic esters were more stable against moderate hydrolysis $[39,40]$. For example, the alcoholic hydroxyl of catechin was selectively substituted by dodecanoyl through 2 steps of esterification and hydrolysis (Scheme 2a). Phenolic hydroxyl and alcoholic hydroxyl can also be directly acylated without affecting each other in the presence of certain additives or by special condition. As shown in Scheme $2 b$, the alcoholic hydroxyl of $\beta$-estradiol was almost completely converted to the alcoholic ester using ethyl acetate as the source of acetyl with the addition of $\mathrm{Zn}$-cluster catalyst [41]. In addition, an investigation of acylation activated by different conditions indicated that microwave will promote the acylation of alcoholic hydroxyl of $\beta$-estradiol compared to conventionally heated synthesis (Scheme $2 b$ ). Similarly, selective acylation of phenolic hydroxyl can be achieved by special reagents and additive such as rubidium fluoride (RbF) [42] and diacyl disulfide [43] which have significantly accelerated the phenolic acylation of $\beta$-estradiol (Scheme 2b).

For polyphenols, different phenolic hydroxyls can be selectively modified according to the difference of charge distribution and steric effect. Amongst them, selective protection/deprotection is the most common method. As a representative polyphenol, there are five hydroxyls in different chemical environments of quercetin, whose selective protection and deprotection route was summarized and presented in Scheme 3. In general, the priority of electrophilic substitution of five hydroxyls is $4 '>7>3>3$ ' $>5$ [44]. Penta-acetylation of quercetin will transform the substitution order into $7>4^{\prime}>3>5>3^{\prime}$ 


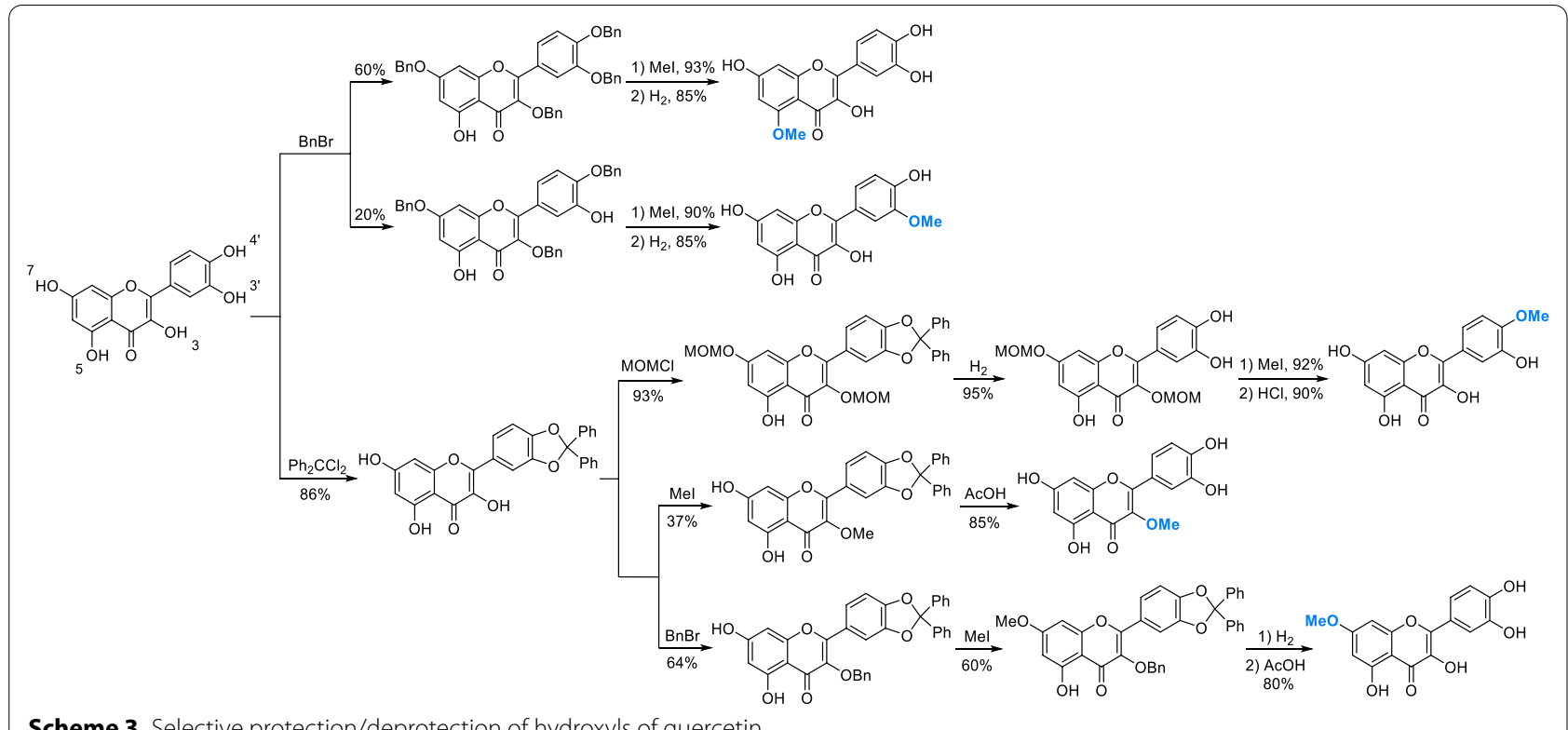

Scheme 3 Selective protection/deprotection of hydroxyls of quercetin

$[45,46]$. By controlling the dosage of reagents, protection of hydroxyls can be kept in the situation of trisubstitution and tetrasubstitution, and then 3'-hydroxyl and 5-hydroxyl can be modified separately. Dichlorodiphenylmethane $\left(\mathrm{Ph}_{2} \mathrm{CCl}_{2}\right)$ could selectively protect two hydroxyls at adjacent position (3' and 4') [47], after which 3-position become more likely attacked by electrophilic reagents such as benzyl bromide and iodomethane.

Selective deprotonation is also a feasible method to selectively modify hydroxyls. Generally, the acidity difference of phenolic hydroxyls will not translate into the selectivity of substitution, while deprotonation will obviously enhance the nucleophilicity of the more acidic phenolic hydroxyl. For instance, 7-OH of genistein was selectively deprotonated by tetrabutylammonium hydroxide $\left(\mathrm{Bu}_{4} \mathrm{NOH}\right)$ and then alkylated preferentially
$[48,49]$ (Scheme 4). Otherwise, there will be a substantial percentage of 4'-OH alkylated products [16].

Classical strategies for derivatization on phenolic ring (Scheme 1B) showed poor regioselectivity. As activated by phenolic hydroxyl, both the ortho and para position on phenolic ring are likely attacked by electrophiles. Thus, it's difficult to obtain derivatives with single and certain component by classical strategies. Recently, some advanced strategies have been developed to regioselectively activate the aromatic $\mathrm{C}-\mathrm{H}$ bond of phenols, which are being gradually applied in the selective derivatization of natural phenols. As a kind of inexpensive transition-metal catalysts, $\mathrm{Cu}(\mathrm{II})$ catalysts were widely researched and applied in the regioselective derivatization of phenols. Amongst them, $\mathrm{Cu}(\mathrm{OAc})_{2-}$ catalyzed aminomethylation seemed promising in the derivatization of natural phenols for its mild conditions,

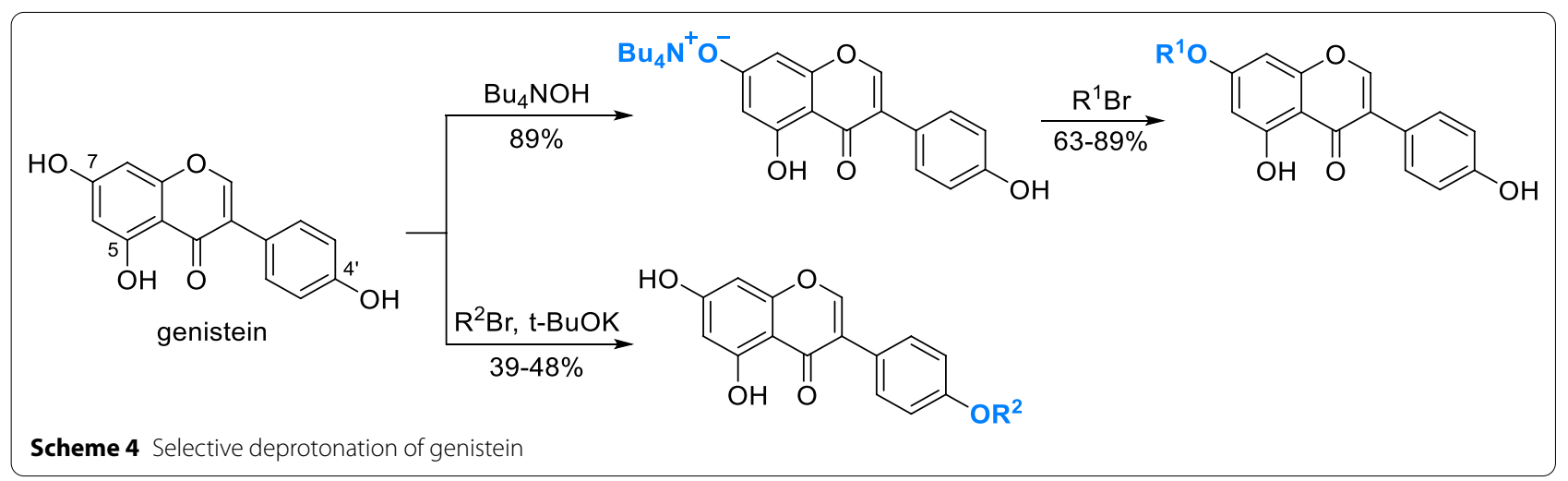


(a) ortho-selective functionalization of phenol fragment

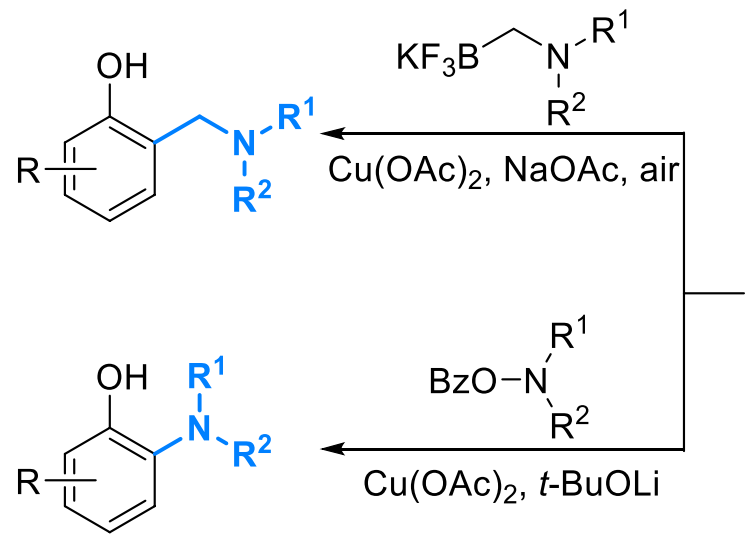

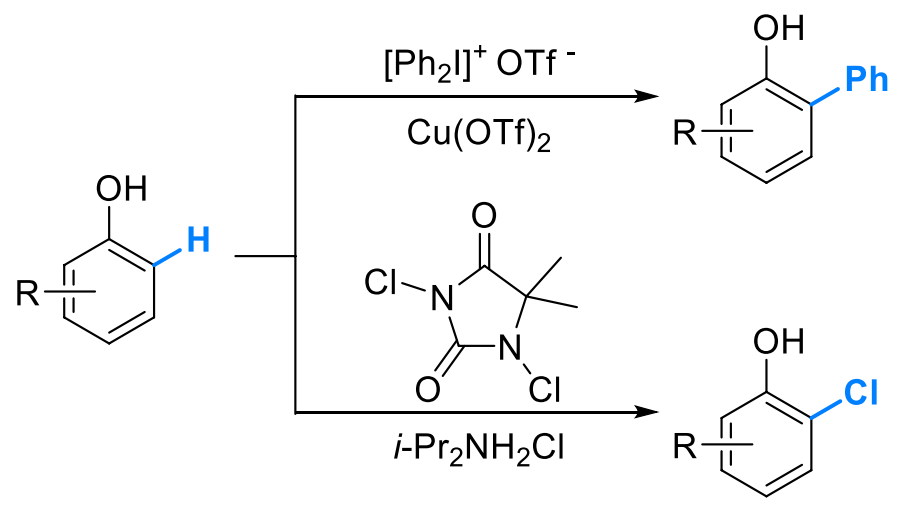

(b) para-selective hydroxylation of methyl phenol fragment

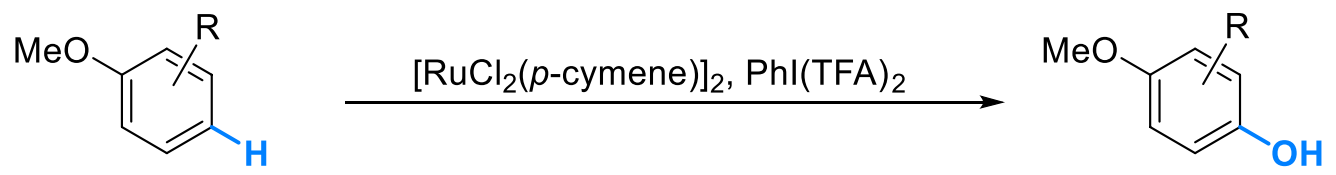

(c) ortho-selective functionalization of phenolic carbamate fragment

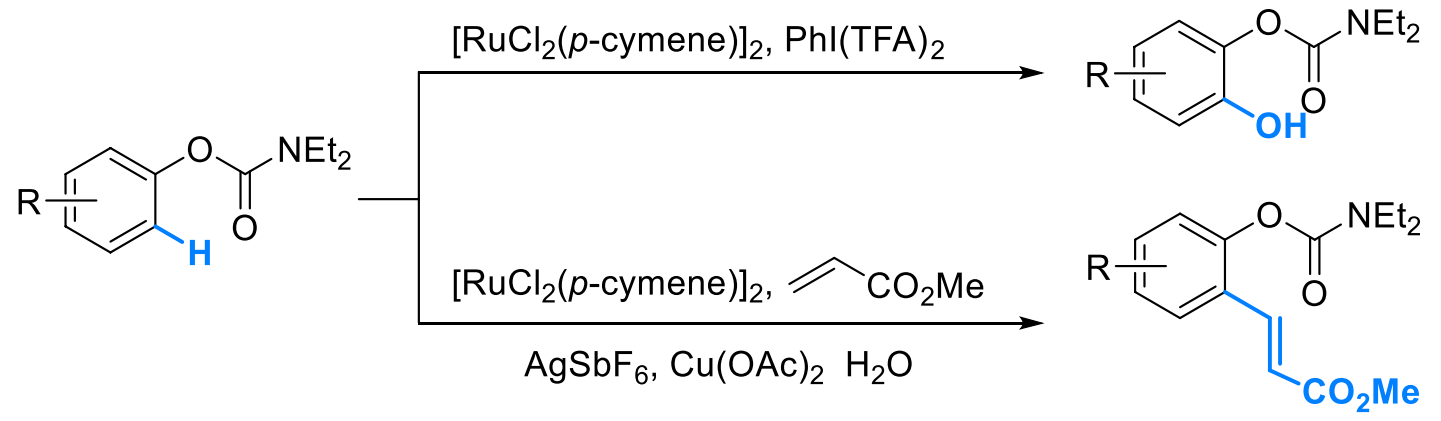

Scheme 5 Advanced strategies by regioselective aromatic $\mathrm{C}-\mathrm{H}$ functionalizations of phenol fragments

accessible reagents, high levels of ortho-selectivity and group-compatibility [50] (Scheme $5 \mathrm{a}) . \mathrm{Cu}(\mathrm{OAc})_{2}$ could also selectively mediate the ortho-amination of phenols with $O$-benzoylhydroxylamines in a moderate yield [51]. Selective ortho-arylation of phenols can be achieved in the presence of $\mathrm{Cu}(\mathrm{OTf})_{2}$ with diaryliodonium salts, while $\alpha$-arylation derivative will be produced when the strategy was applied in 2-naphthol [52]. Catalyzed by low concentration of ammonium salt, phenols can be ortho-selectively mono-chlorinated with 1,3-dichloro5,5-dimethylhydantoin (DCDMH) [53], which showed highly practical as all reagents were commercially available. Catalysis of $\left[\mathrm{RuCl}_{2}(\mathrm{p} \text {-cymene })\right]_{2}$ was also a common strategy for regioselective derivatization, by which methoxyphenols can be para-selectively hydroxylated with the oxidant of PhI(TFA) ${ }_{2}$ [54] (Scheme 5b). In the same condition, phenolic carbamates were selectively hydroxylated on the ortho-position (Scheme $5 \mathrm{c}$ ). $\left[\mathrm{RuCl}_{2} \text { (p-cymene) }\right]_{2}$ also catalyzed the selective ortho-alkenylation of phenolic carbamates, which was practicable for a large scope of substituted substrates [55]. After hydrolysis, phenolic carbamates can be converted to phenols.

\subsection{Derivatization strategies of phenylpropanoid fragments}

\subsubsection{Classical derivatization strategies of phenylpropanoid fragments}

Phenylpropanoid fragments, including propyl-benzene, propenyl-benzene and allyl-benzene, are the nuclear structures of various natural phenols including lignans, 
neolignans, stilbenes and catechins. The three fragments can be transformed to each other by hydrogenation, dehydrogenation or isomerization (Fig. 5). Generally, hydrogenation proceeds in the catalysis of transitionmetal such as palladium and nickel using hydrogen gas or ammonium formate as hydrogen source. With the presence of nickel chloride, propenyl-benzene and allylbenzene fragments can also be hydrogenated by sodium borohydride [56]. Dehydrogenation of propyl-benzenes will give the priority to generating conjugated products such as propenyl-benzenes [57, 58]. Propenyl-benzenes could be transformed by isomerization of allyl-benzenes with miscellaneous methods which have been reviewed in great detail in previous literature [59]. Nevertheless, mutual transformation of phenylpropanoid fragments had relatively little influence on the bioactivity of natural phenols. For instance, both the isomerization of magnolol and the hydrogenation of honokiol made little contribution to improving or reducing the cytotoxicity against Hep-G2 cells, as the $\mathrm{IC}_{50}$ values changed little (Fig. 5).

Compared with mutual transformation of phenylpropanoid fragments, introducing functional groups or specific structures was more likely to promote the bioactivity. As shown in Scheme 6, the pharmacological activities of hydroxychavicol [60], trans-anethole [61] and 4'-O-methylhonokiol [62] were markedly enhanced by introducing acetoxyl, hydroxyl and bromine respectively into the phenylpropanoid fragments. In addition to those strategies for aromatic ring which have been reviewed in Scheme 1, the side chain of phenylpropanoid fragments offer various possibilities for structural derivatization. Taking allyl-benzene fragment as a template (Scheme 6), it could be converted into an abundance of derivatives by halogenated intermediates. However, halogenation of different conditions will generate diverse types of products, which have been comprehensively reviewed previously
[63]. To avoid the halogenation of aromatic hydrogen, the electron density should be reduced by protecting phenolic hydroxyl or introducing electron-withdrawing group. Theoretically, addition of olefin with hypohalous acid could generate halogenated alcohol, but it's never reported for allyl-benzene fragments. As an alternative approach, allyl-benzenes can be transformed to halogenated alcohol by $N$-halogenated succinimide in the presence of water and catalytic amount of ammonium acetate [64] (Scheme 6d). Addition of allyl-benzene with haloid acid in general condition mainly provided Markovnikov's products (Scheme 6e), while in the presence of initiator the anti-Markovnikov derivatives can be produced (Scheme 6f). In recent years, the initiator-free anti-Markovnikov hydrobromination has been developed with good scalability and reproducibility, which applied the solution of $\mathrm{HBr}$ in acetic acid and required air to be passed through solution in advance [65] (Scheme 6g). Product of single configuration can be obtained by advanced conditions especially rhodium catalytic system [66-68]. Hydroboration with diboride will generate 1,2-bis(boronates) [69] which can be further oxidated to vicinal diol (Scheme 6k). The participation of rhodium [70] and platinum [71] catalysts will lead to enantioselective products. In the presence of osmium tetroxide $\left(\mathrm{OsO}_{4}\right)$, allyl-benzene fragments can be directly oxidized to cis-vicinal diol (Scheme 6l), just as the modification of hydroxychavicol [60]. Simple oxidation using molecular oxygen catalyzed by palladium acetate was also developed, but it will furnish a mixture of isomers of vicinal diols [72] (Scheme 6m).

As an important strategy widely applied for natural phenols such as chavicol and honokiol to generate diverse derivatives [73, 74], allyl-benzene fragments can be epoxidized by peroxy acid, after which a great variety of nucleophilic groups including hydroxyl, alkoxyl,

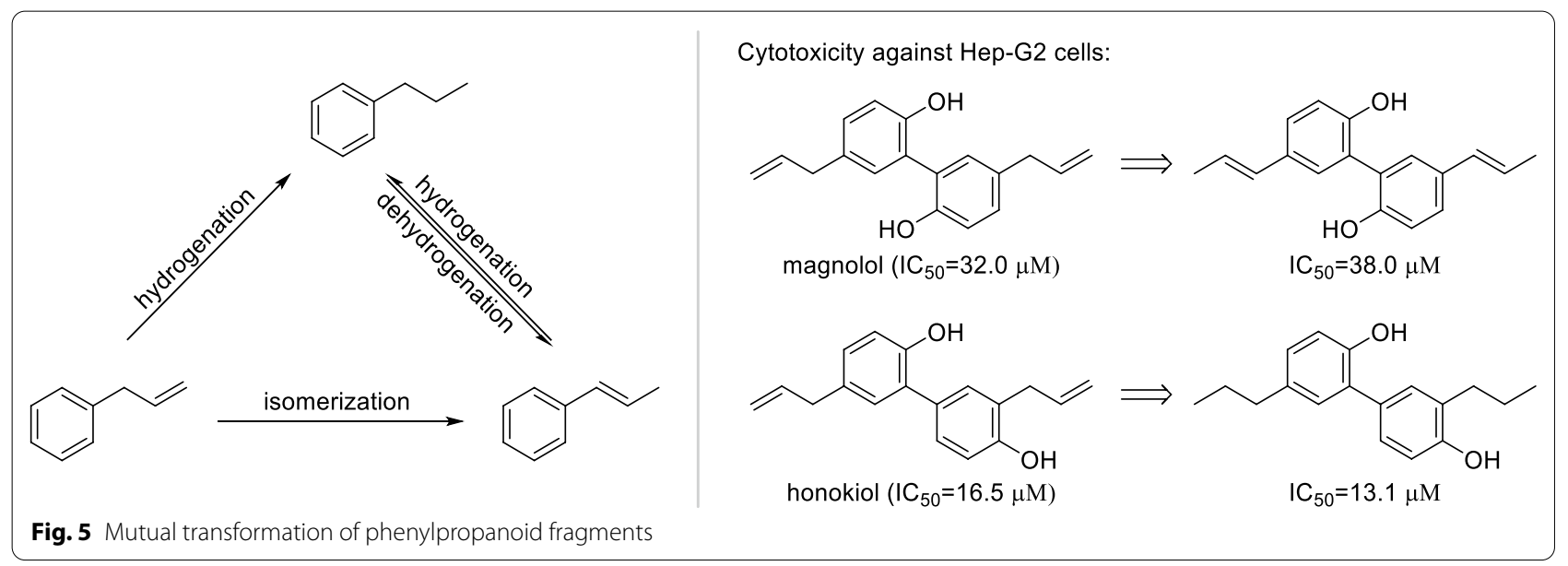




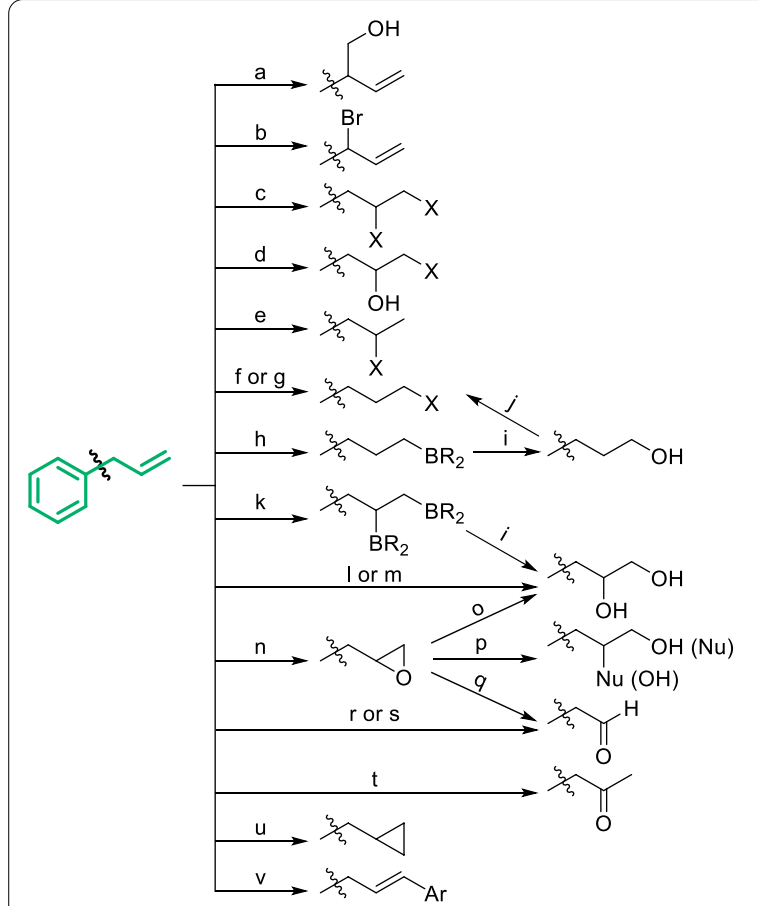

Antiproliferative activity $\left(\mathrm{IC}_{50}\right)$ of hydroxychavicol and its derivatives against Hela cells

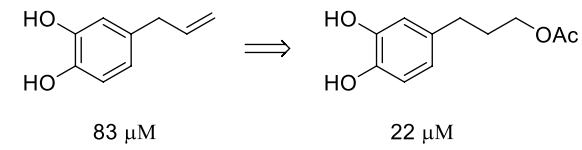

Vascular permeability inhibition rate of trans-anethole and its derivatives:

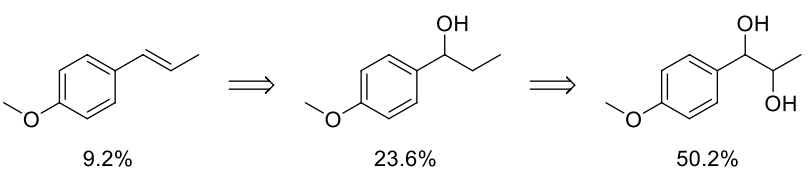

Potentiation $\left(\mathrm{EC}_{50}\right)$ of $\mathrm{I}_{G A B A}$ by 4 '-O-methylhonokiol and its derivatives:

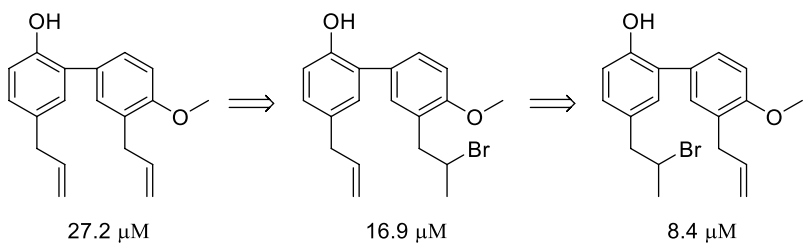

Scheme 6 Classical derivatization strategies of phenylpropanoid fragments. Common conditions: $\mathbf{a}\left(\mathrm{CH}_{2} \mathrm{O}\right)_{\mathrm{n}} / t \mathrm{BuOK} \mathbf{b} \mathrm{NBS} \mathbf{c} \mathrm{X}_{2}$ or RX/Oxidant $\mathbf{d}$ $\mathrm{NXS} / \mathrm{NH}_{4} \mathrm{OAc} / \mathrm{H}_{2} \mathrm{O}$ e $\mathrm{HX} \mathbf{f} \mathrm{HX} /$ initiator $\mathbf{g} \mathrm{HBr} / \mathrm{AcOH} \mathbf{h} \mathrm{R}_{2} \mathrm{BH} \mathbf{i} \mathrm{H}_{2} \mathrm{O}_{2} /$ base $\mathbf{j} \mathrm{HX} \mathbf{k} \mathrm{B}_{2} \mathrm{R}_{2} \mathbf{I} \mathrm{OsO}_{4} \mathbf{m} \mathrm{Pd}(\mathrm{OAc})_{2} / \mathrm{O}_{2} /$ base $\mathbf{n}$ peroxy acid o $\mathrm{H}_{2} \mathrm{O} \mathbf{p}$ nucleophile $\mathbf{q}$ $\mathrm{H}_{5} \mathrm{IO}_{6}$ or $\mathrm{NaIO}_{4} \mathbf{r} \mathrm{OsO}_{4} / \mathrm{NaIO}_{4} \mathbf{s} \mathrm{O}_{3} \mathbf{t} \mathrm{PdCl}_{2} / \mathrm{O}_{2} \mathbf{u} \mathrm{CH}_{2} \mathrm{I}_{2} / \mathrm{Et}_{2} \mathrm{Zn} / \mathrm{acid} \mathbf{v} \mathrm{ArX} / \mathrm{Pd}(\mathrm{OAC})_{2} / \mathrm{PPh}_{3}$

aryloxyl, halogen and amino could be introduced [75, 76] (Scheme $6 \mathrm{n}-\mathrm{p}$ ). Affected by periodic acid or periodate, epoxide can be cleaved and transformed to corresponding aldehyde [77, 78] (Scheme 6q). The oxidative cleavage of allyl-benzene fragments can also be directly achieved by $\mathrm{OsO}_{4}$ in the presence of excess of $\mathrm{NaIO}_{4}$ as co-oxidant (Scheme 6-r), which is easier operated than oxidative cleavage by ozonization [62] (Scheme 6s). In addition, allyl-benzene can be transformed to propiophenone by Wacker-type oxidation by the catalysis of $\mathrm{PdCl}_{2}$ [79] (Scheme 6t), meanwhile the internal olefins such as propenyl-benzene will not be influenced. Reaction of allyl-benzene with carbene will generate cyclopropanetype products [80] (Scheme 6u). Furthermore, Heck reaction of allyl-benzene could introduce aryl in the terminal of allyl-benzenes (Scheme 6v), as applied in the derivatization of methyl eugenol [81].

For expanding the diversity of derivatives, the skeleton of natural phenols can be reconstructed by ring formation. As a common fragment of natural phenols, $o$-allyl phenol can be oxidized and cyclized to give methyl benzofuran by the catalysis of $\mathrm{PdCl}_{2}$, which is known as Wacker-type oxidative cyclization [82] (Scheme 7). In the presence of copper salts, oxidative cyclization could undergo without molecular oxygen
[83]. By intramolecular acid catalyzed cyclization, $o$-allyl phenol can be converted into methyl dihydrobenzofuran [84], which can also be obtained by the hydrogenation of methyl benzofuran [85]. However, acid-catalyzed polymerization might be observed if there are multi-olefin groups in the structure of natural phenols. Through hydroboration and intramolecular dehydration in the presence of diisopropyl azodicarboxylate (DIAD) and triphenylphosphine, $o$-allyl phenols will be transformed into dihydrochromenes [86], which can also be obtained by the reflux of phenylpropanol intermediate with hydrobromic acid [87]. Oxidation of phenylpropanol intermediate by pyridinium chlorochromate (PCC) followed with condensation will generate 2-alkoxydihydrochromenes [86].

In addition, a special strategy has been developed for selective derivatization of side chain taking the advantage of the ortho-effect of phenolic hydroxyl, as the side chain in the ortho position of phenolic hydroxyl has higher priority in some reactions due to the intramolecular and intermolecular interaction. It's reported that the epoxidation of allyl of honokiol were obviously promoted by the intermolecular hydrogen bonding between m-CPBA and ortho-hydroxy, and the epoxide in the ortho-position of phenolic hydroxyl was more likely to be attacked by nucleophilic groups [74] (Fig. 6). 


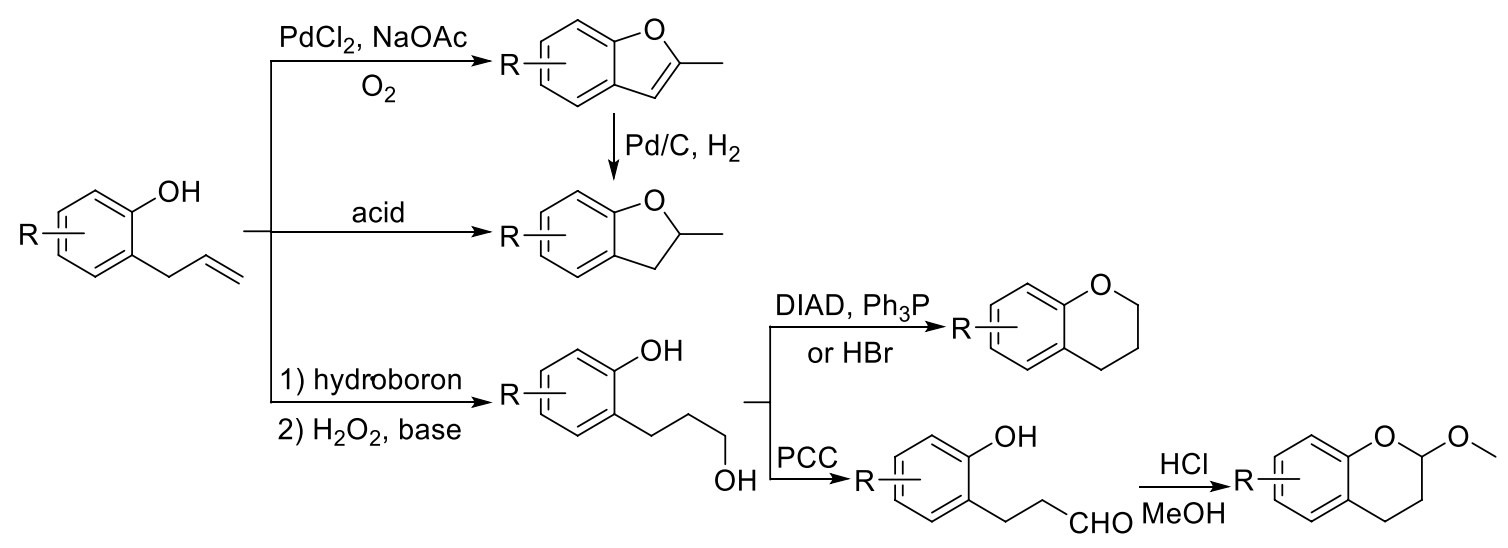

Scheme 7 Cyclization strategies of o-allyl phenol fragments

\subsubsection{Rapid and selective derivatization strategies of phenylpropanoid fragments}

The introduction of functional groups into phenylpropanoid fragments always required several steps by classical strategies, which caused low efficiency, poor selectivity. It's also a great waste for precious natural phenols. Recently, advanced strategies have been developed with high efficiency and selectivity. Allylbenzenes can be directly oxidized into primary allylic alcohols by the catalysis of $\left[\mathrm{Pd}\left(\mathrm{PPh}_{3}\right)_{4}\right]$ with $\mathrm{H}_{2} \mathrm{O}, \mathrm{CO}_{2}$ and 2,5-di-tert-butyl-1,4-benzoquinone $\left(2,5-t \mathrm{Bu}_{2} \mathrm{BQ}\right)$ as reagents (Scheme $8 \mathrm{a}$ ). With ultrasonic treatment, allylbenzenes can be simply transformed to terminal ester by 2,3-dicyano-5,6-dichlorobenzoquinone (DDQ), while for propyl-benzene acyloxylation preferentially occurred in the benzyl (Scheme $8 \mathrm{~b}$ ). In the presence of triazolesubstituted chiral iodoarene, allyl-benzenes or propylbenzenes can be converted into chiral benzyl alcohols by an enantioconvergent hydroxylation (Scheme 8c). Recently, a $\mathrm{NH}_{4} \mathrm{I}$-promoted direct sulfenylation of was

(a) terminal hydroxylation

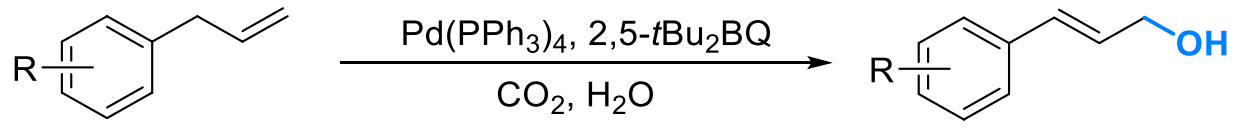

(b) terminal and benzylic acyloxylation<smiles>[R][R]1ccc(CC=C)cc1</smiles>

(c) enantioconvergent benzylic hydroxylation<smiles>C=CCC1=CC=C[R]C=C1</smiles>
a, $\mathrm{CuBr}, \mathrm{NaBr}, \mathrm{m}-\mathrm{CPBA}$ blue led<smiles>[R]=CC(O)c1ccncc1</smiles>

a:<smiles>COc1cccc([C@@H](O[SnH3])c2cn(Cc3ccccc3)nn2)c1I</smiles>

(d) $\mathrm{H}_{2} \mathrm{O}$-controlled bis-sulfenylation and hydroxysulfenylation<smiles>[R][R]1cccc(CC=C)c1</smiles>

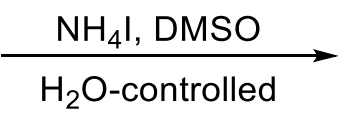<smiles>[R][X]C(CSCC)Cc1ccccc1</smiles>
or<smiles></smiles>

Scheme 8 Direct hydroxylation, acyloxylation and sulfenylation of phenylpropanoid fragments 
(a) linear-selective and branch-selective allylic amination

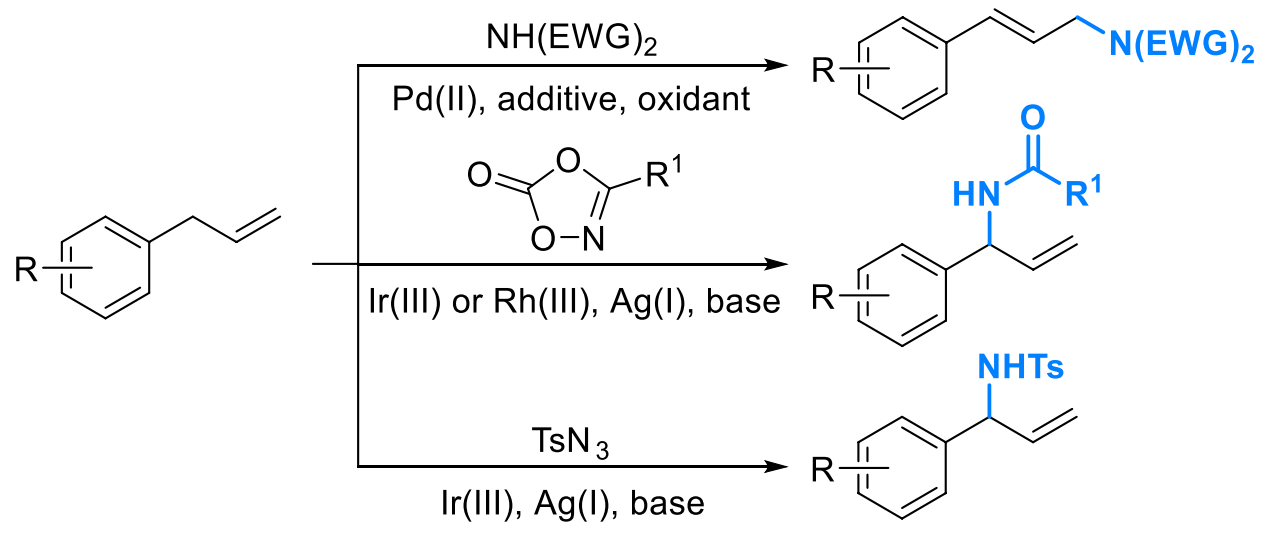

(b) light-activated benzylic amidation<smiles>[R][R]1ccc(CC=C)cc1</smiles>

(c) two-steps enantioselective amination

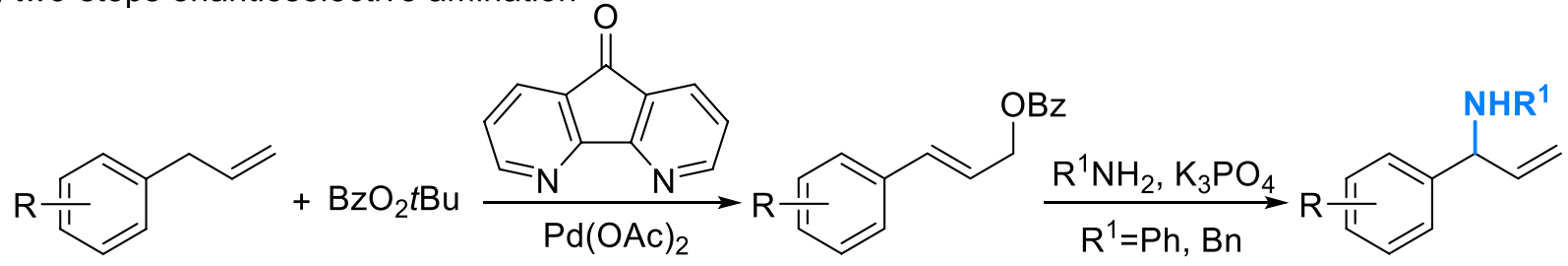

Scheme 9 Rapid and selective amination of phenylpropanoid fragments

accomplished in a special way controlled by water. A series of $\beta$-hydroxysulfide were produced from allylbenzenes in mixed solution of DMSO and water, while bismethylsulfanes can be obtained in anhydrous system (Scheme 8d).

Amino was an important group to improve bioactivity and realize diversity-oriented derivatization. As the classical strategy, it will take several steps to introduce amino onto phenylpropanoid fragments through the halogenated intermediate. Direct amination of allyl-benzenes can be activated by transition-metal catalysis or photocatalysis. The catalysis systems of $\mathrm{Pd}(\mathrm{II})$ promoted the coupling of allyl-benzenes and secondary amine with electron withdrawing groups (EWG) such as acyl and tosyl, which always generated linear allylic amines [88-91] (Scheme 9a). A series of branch-selective allylic amidation using dioxazolones were also developed, which proceeded in a mild condition catalyzed by $\operatorname{Ir}(\mathrm{III})$ or $\mathrm{Rh}(\mathrm{III})$ and extended to a wide scope of amide [92-94]. Branchselective sulfamidation can be promoted in similar condition using tosyl azides $\left(\mathrm{TsN}_{3}\right)$ as the nitrogen source [95].
A novel visible-light-catalyzed reaction could directly introduce $N$-methoxyl amide into benzyl position employing 9,10-dicyanoanthracene (DCA) as an absorbing photoredox catalyst (Scheme 9d), but the universality was unknown as there was only few cases related to phenylpropanoid fragments in this research [96]. Allylbenzenes can also be aminated mediately by benzoate with high enantioselectivity [97] (Scheme 9e). Although it underwent two steps, the conditions and reagents were relatively available. A wide scope of nucleophiles was reported in this work, but only phenylamine and benzylamine were successfully applied for allyl-benzenes.

Direct introducing arylation and olefination onto phenylpropanoid fragments has seldom been reported up to now, as catalytic formation of inactive $\mathrm{C}-\mathrm{C}$ bond remains a challenge. At present, a cross-coupling reaction in the presence of $\mathrm{Pd}(\mathrm{OAc})_{2}$ and tricyclohexyl phosphine $\left(\mathrm{PCy}_{3}\right)$ has been established to selectively introduce aryls into the branch of allyl-benzenes (Scheme 10a), which was reported to be appropriate for a wide scope of aryl groups [98]. Catalyzed by $\left[\mathrm{Cp} * \mathrm{RhCl}_{2}\right]_{2}$, allyl-benzene fragments 
(a) branch-selective arylation

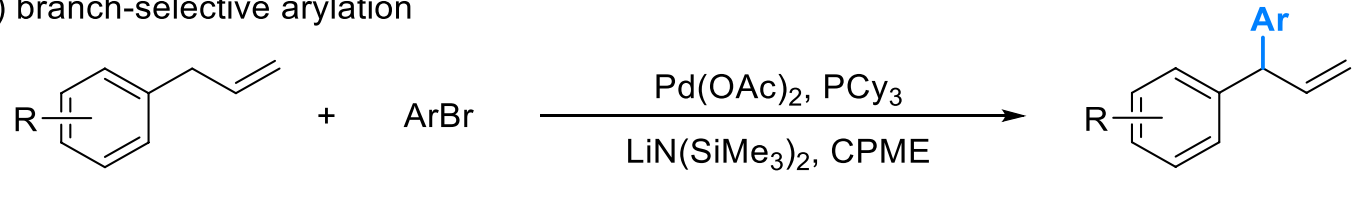

(b) direct heteroarylation

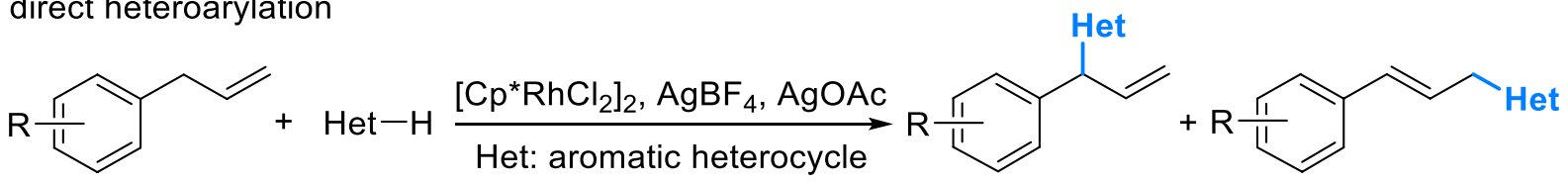

(c) linear-selective olefination

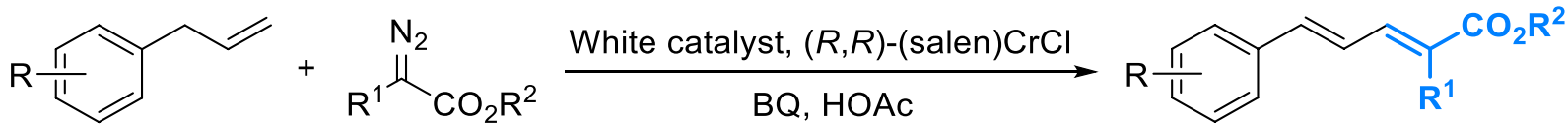

Scheme 10 Direct arylation and olefination of allyl-benzene fragments

can be activated to give heteroaromatic products with poor selectivity [99] (Scheme 10b). Activated by White catalyst and (salen) $\mathrm{CrCl}$, allyl-benzene fragments can be directly transformed to conjugated polyene derivatives employing $\alpha$-diazo esters with good stereoselectivities [100] (Scheme 10c).

Direct hydroxyalkylation of allyl-benzene fragments can be enabled by basic catalyst, but it showed poor stereoselectivity [101]. In recent years, a series of transition metal-catalyzed strategies have been developed to keep product in a single enantiomer. Amongst them, oxidative borylation seemed to be the most promising strategy with moderate condition and low cost (Scheme 11). Hydroxyalkyl derivatives of different configurations can be obtained by employing different diborides and chiral phosphoric acids as ligands [102, 103]. Allyl-benzene fragments can also be diastereoselectively hydroxyalkylated catalyzed by ruthenium and iridium catalysts through a cross-metathesis/ isomerization/allylboration sequence [104]. Besides, a hydroxyalkylation enabled by the combination of photoredox, iridium and chromium catalysis could exclusively produce 1-hydroxyl-1-aryl-methyl derivative as a single diastereomer from cis/trans mixture of electronrich allyl-benzenes [105].

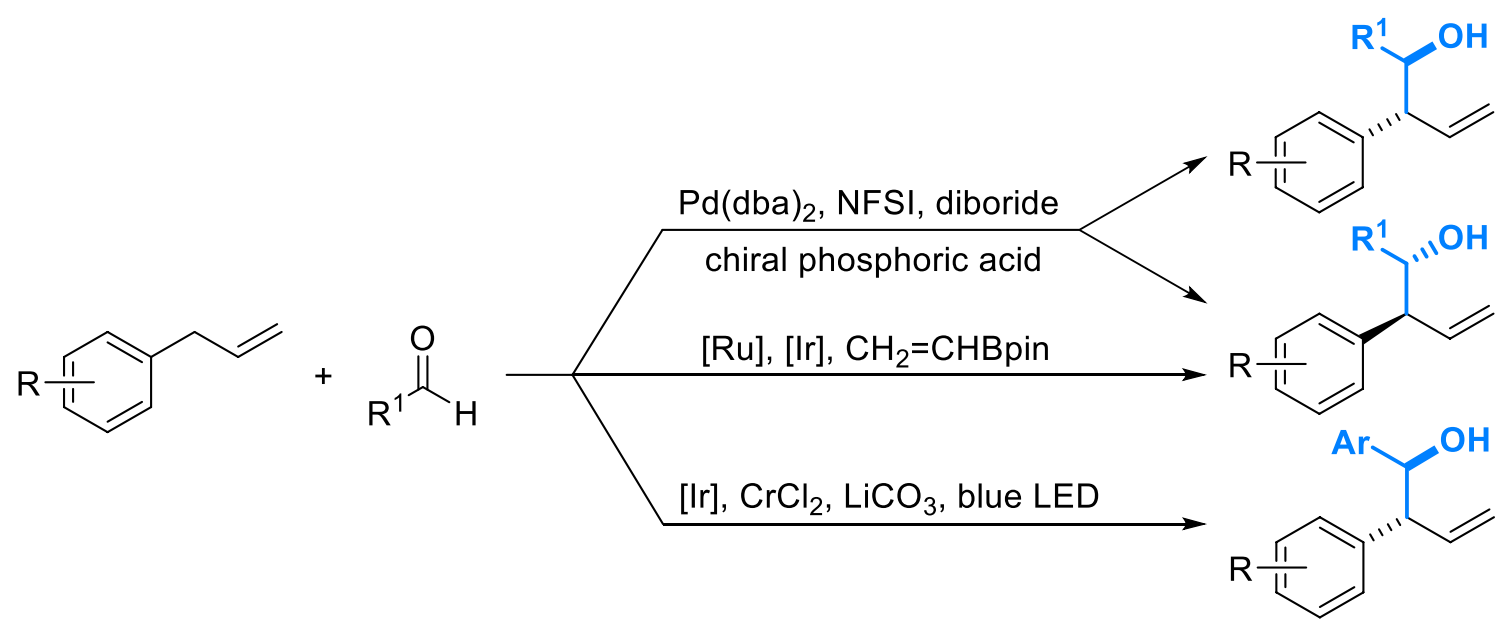

Scheme 11 Diastereoselective hydroxyalkylation of allyl-benzene fragments 


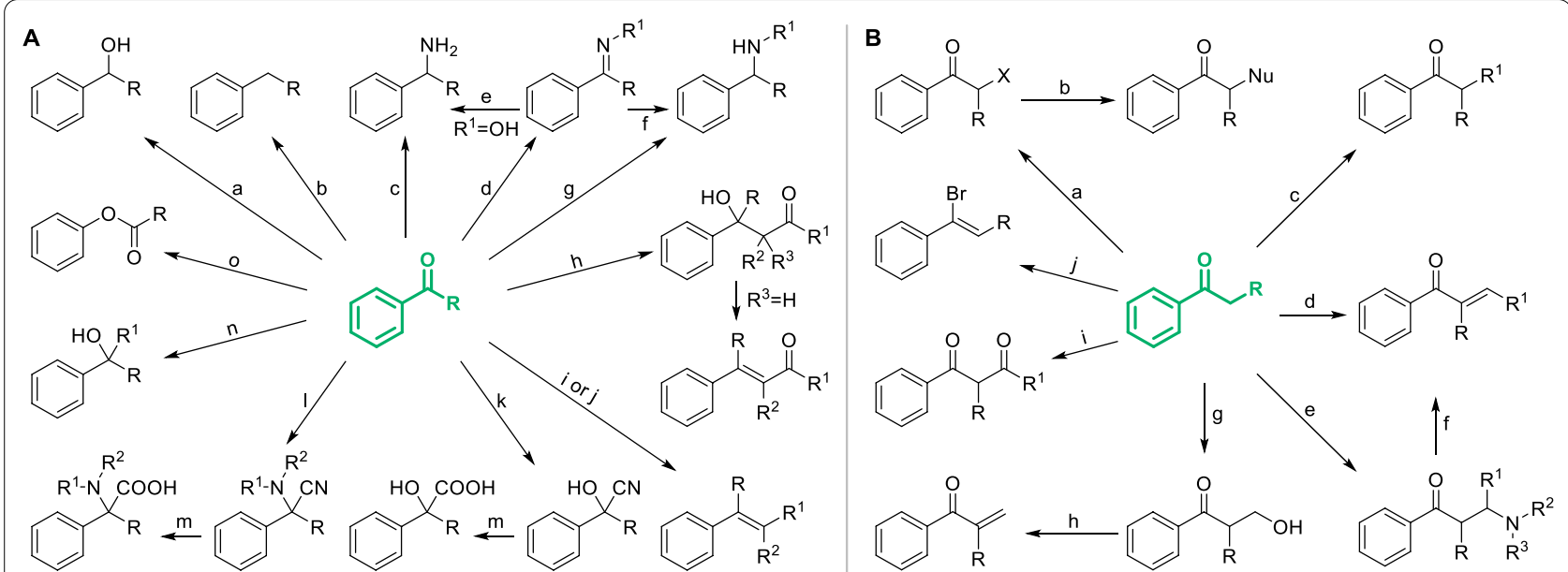

Scheme 12 Classical derivatization strategies of phenylketone fragments. A Derivatization of carbonyl. Common conditions: a NaBH $/$ alcohol b $\mathrm{Zn}-\mathrm{Hg} / \mathrm{HCl}$ (Wolff-Kishner reduction) or $\mathrm{NH}_{2} \mathrm{NH}_{2} /$ base/ high temperature (Clemmensen reduction) or $\mathrm{HS}\left(\mathrm{CH}_{2}\right)_{3} \mathrm{SH}_{3} \mathrm{BF}_{3} \cdot \mathrm{Et}_{2} \mathrm{O}$ or $\mathrm{NaBH}_{4} / \mathrm{TFA}(\mathrm{Gribble}$ reduction for $\mathrm{R}=$ aryl) $\mathbf{c} \mathrm{NH}_{4} \mathrm{OAc} / \mathrm{NaBH}_{3} \mathrm{CN} /$ alcohol $\mathbf{d} \mathrm{R}^{1} \mathrm{NH}_{2}$ e Pd/H or $\mathrm{Zn} / \mathrm{H}^{+} \mathbf{f} \mathrm{NaBH} / \mathrm{alcohol} \mathbf{g} \mathrm{R}^{1} \mathrm{NH}_{2} / \mathrm{NaBH}_{4} / \mathrm{Lewis}$ acid $\mathbf{h} \mathrm{R}^{1} \mathrm{COCH} \mathrm{R}^{2} \mathrm{R}^{3} \mathbf{i} \mathrm{CH}_{2} \mathrm{R}^{1} \mathrm{R}^{2}$ $\left(R^{1}, R^{2}=\right.$ elctron withdrawing group) $\mathbf{j} \mathrm{Ph}_{3} \mathrm{P}=C \mathrm{C}^{1} \mathrm{R}^{2}$ (Wittig reaction) or (OEt) ${ }_{2} \mathrm{POCHR} \mathrm{R}^{2} \mathrm{R}^{2}$ (Wittig-Horner reaction) $\mathbf{k} T M S C N / L$ ewis acid I NHR ${ }^{1} \mathrm{R}^{2}$ / (EtO) ${ }_{2} \mathrm{POCN} \mathbf{m} \mathrm{H}_{2} \mathrm{O} \mathbf{n} \mathrm{R}^{1} \mathrm{MgBr}$ or $\mathrm{R}^{1} \mathrm{Li}$ o peroxy acid; $\mathbf{B}$ Derivatization of acetophenone fragments. Common conditions: $\mathbf{a}$ halogenating reagents $\mathbf{b}$ nucleophile $\mathbf{c} \mathrm{R}^{1} \mathrm{X}$, base $\mathbf{d} \mathrm{R}^{1} \mathrm{CHO}$, base e $\mathrm{R}^{1} \mathrm{CHO}, \mathrm{NHR}^{2} \mathrm{R}^{3} \mathbf{f} \mathrm{CH}_{3} / /$ base/ $\mathbf{g} \mathrm{HCHO}$, base $\mathbf{h}$ oxalic acid $\mathbf{i} \mathrm{RCOOEt}$, base $\mathbf{j} \mathrm{PBr}_{3}$

\subsection{Derivatization strategies of phenylketone fragments 2.4.1 Classical derivatization strategies of phenylketone fragments}

As the basic scaffold of chalcones, flavonoids and polyketides, phenylketone is also a very common fragment of natural phenols, which always exist in the form of diarylketone, acetophenone, propiophenone, acrylophenone, benzoic acid and ester. Modification of phenylketone fragments can create an enormous variety of different derivatives and even change the skeleton of natural phenols, also greatly affecting the bioactivity. As a famous natural phenol with excellent pharmacological effects, emodin was converted into a mono-ketone derivative which showed significantly stronger antifungal activity toward Schizosaccharomyces pombe [106] (Fig. 7a). Similar phenomena has been observed in the research of isoflavone derivatives (Fig. $7 \mathrm{~b}$ ), whose radical scavenging ability was greatly enhanced after reduction of phenylketone fragments [107]. Introducing specific groups onto phenylketone fragments may also influenced the biological activity, such as the addition of pyrazole onto chalcone derivative obviously improving the inhibition against Pim-1 Kinase [108] (Fig. 7c). More classical strategies were presented in Scheme 12 for designing diversity-oriented derivatization based on phenylketone fragments.

As the classical strategies, phenylketone fragments offered two kinds of possibilities for structural derivatization: the carbonyl and aliphatic side chains. The carbonyl of phenylketone can be transformed into various structures by classical reactions (Scheme 12A). Amongst them, reduction of carbonyl into methylene can be achieved by several methods (Scheme 12A-b). Classical strategies mainly including Wolff-Kishner reduction and Clemmensen reduction were appropriate for phenylketone with good stability. The approach through dithiane intermediate could convert carbonyl into methylene in a mild condition, which was widely applied in the synthesis and modification of natural products [109]. Carbonyl can also be mildly reduced using triethylsilane and acid catalyst such as boron trifluoride etherate $\left(\mathrm{BF}_{3} \cdot \mathrm{Et}_{2} \mathrm{O}\right)$. Diarylketone can be easily converted into diarylmethane by Gribble reduction [110]. For anthracene-9,10-diones such as emodin, the reduction of carbonyls can be controlled to mono-reduction by $\mathrm{SnCl}_{2}$ in mixed acid, and the carbonyl close to hydroxyl can be protected probably due to the intramolecular hydrogen bond [106]. Carbonyl can also be reduced to primary amine in the presence of $\mathrm{NH}_{4} \mathrm{OAc}$ and $\mathrm{NaBH}_{3} \mathrm{CN}$ [111] (Scheme 12A-c) or via the intermediate of oxime [112, 113] (Scheme 12A-e). The condensation and hydrogenation can be combined in one-pot by the catalysis of Lewis acid such as $\mathrm{CeCl}_{3}$ [114] and titanium isopropoxide [115] (Scheme 12Ag). As a common strategy, phenylketone fragments can be translated to hydroxyphenylacetone or $\alpha, \beta$ unsaturated ketone by Aldol reaction (Scheme 12A-h). Similarly, nucleophilic addition followed by elimination of phenylketone could provide styrene derivatives with elctron-withdrawing groups (Scheme 12A-i). Through Wittig-type reactions, more kinds of styrene derivatives 


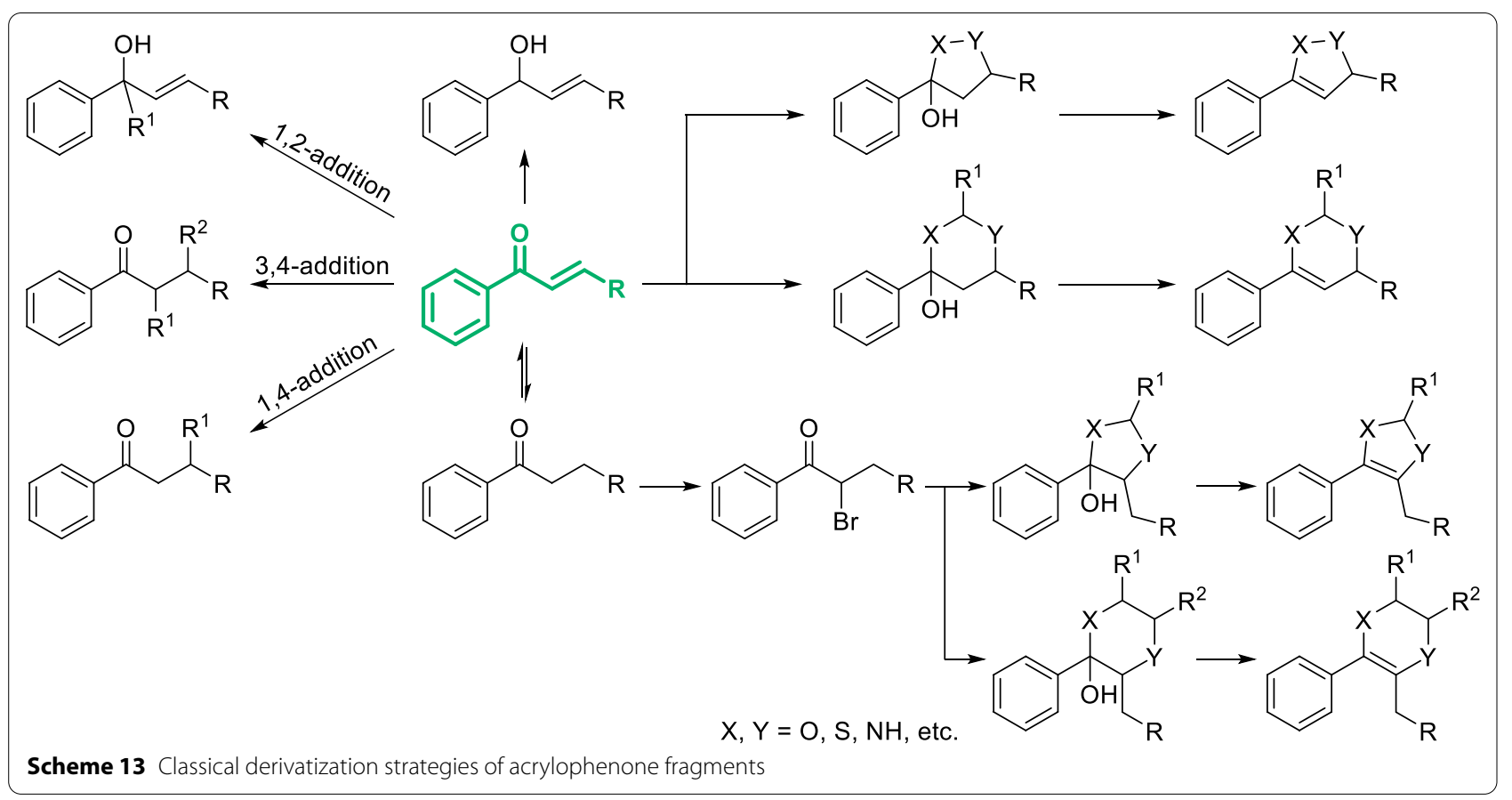

can be obtained (Scheme 12A-j). By an addition reaction with cyanotrimethylsilane (TMSCN), phenylketone can be converted into $\alpha$-cyanoalcohol derivatives (Scheme 12A-k). In the presence of amine and cyanide such as diethyl cyanophosphate $\left(\mathrm{PO}(\mathrm{OEt})_{2} \mathrm{CN}\right)$ and acetone cyanohydrin, phenylketone can also be translated to $\alpha$-cyanoamines, which was known as Strecker reaction (Scheme 12A-l). $\alpha$-Cyanoalcohols and $\alpha$-cyanoamines can be further hydrolyzed and generate to $\alpha$-hydroxyacid and $\alpha$ - aminoacid, respectively (Scheme 12A-m). Nucleophilic addition with organometallic compounds such as organolithium and Grignard reagent will convert phenylketone into $\alpha$-alkyl or $\alpha$-aryl alcohol derivatives (Scheme 12A-n). Moreover, phenylketone fragments can be transformed to corresponding phenylester by peroxy acid which was known as Baeyer-Villiger oxidation [116] (Scheme 12A-o).

For acetophenone fragments, there were many options of derivatization on the aliphatic side chains. The $\alpha$-hydrogen of carbonyl can be replaced by halogen (Scheme 12B-a), which can be further substituted by electrophile such as amine (Scheme 12B-b). Acetophenone fragments could also react as nucleophile with halohydrocarbon or carbonyl compound to lengthen the carbon chain (Scheme 12B-c,d). The reaction with carbonyl compound was known as Adol-type condensation. Mannich reaction is a classical strategy converting acetophenone fragments to $\alpha$-aminomethyl products [117] (Scheme 12B-e), which can be further transformed into $\alpha, \beta$-unsaturated ketone by Hofmann elimination
(Scheme 12B-f). $\alpha$-Hydroxymethyl product can be obtained by Tollens condensation (Scheme 12B-g), and eliminated in the presence of oxalic acid (Scheme 12Bh). Acetophenone fragments can also be $\alpha$-acylated by carboxylic esters which is known as Claisen condensation, while formyl can be introduced by formate [118] (Scheme 12B-i). In addition, acetophenone fragments with stable enol form can be brominated in the presence of phosphorus tribromide (Scheme 12B-j), which can be further substituted by nucleophiles [119].

Derivatization strategies of acrylophenone fragments were generally similar to those of phenylketones and phenylpropanoids. However, catalytic hydrogenation of acrylophenone will preferentially occur at $\mathrm{C}-\mathrm{C}$ double bond, while the carbonyl could be selectively hydrogenated by sodium borohydride with the addition of $\mathrm{CeCl}_{3}$ which is known as Luche reduction [120] (Scheme 13). Dehydrogenation of propiophenone fragments always employ 2,3-dicyano-5,6-dichlorobenzoquinone (DDQ) as oxidant [121]. Recently, an efficient, economic and general $\mathrm{Pd}(\mathrm{OAc})_{2}$-catalyzed dehydrogenation was developed using molecular oxygen as the oxidant [122], offering a new option for this transformation. 1,2-addition and 3,4-addition of acrylophenone fragments were also conducted in similar way with those of phenylketone and allylbenzene fragments which has been respectively reviewed in Schemes 12 and 6. As a particular strategy, 1,4-addition could introduce various groups including hydroxyl, alkoxyl, amino and alkyl with electronwithdrawing groups onto $\beta$-carbon of acrylophenone 


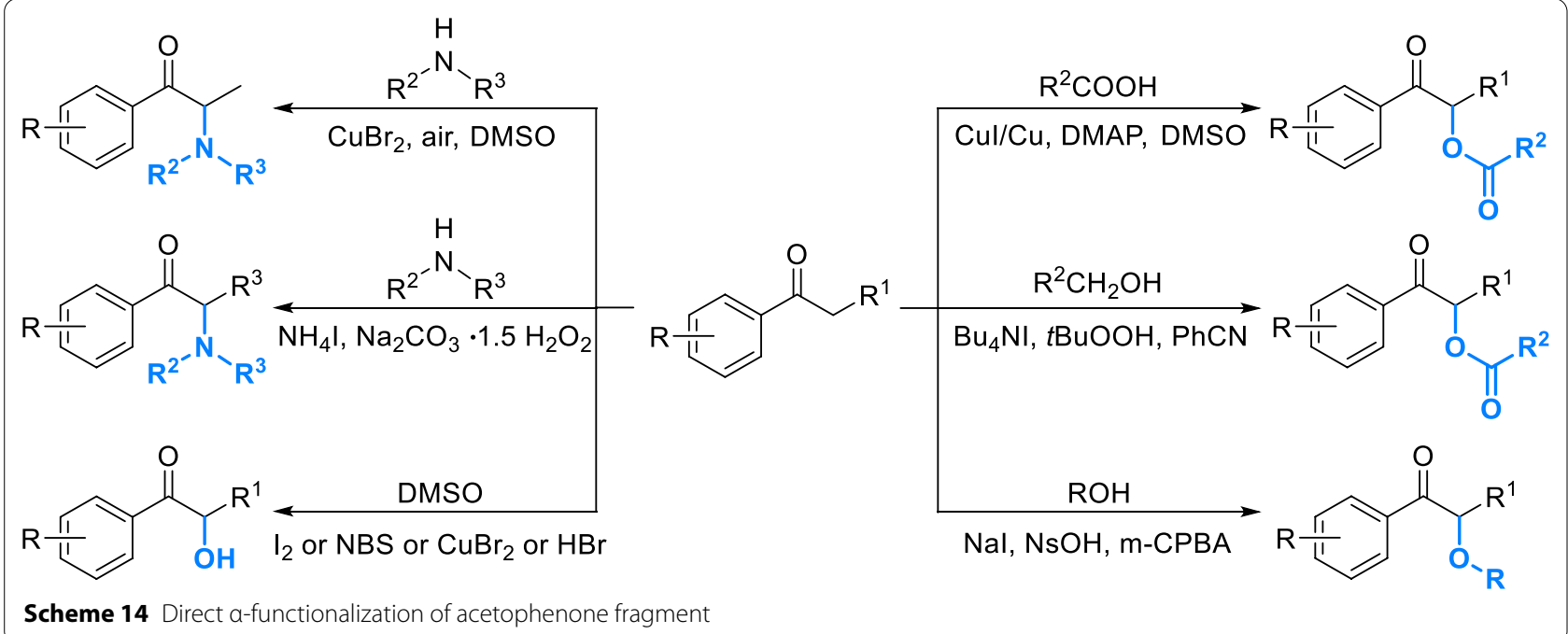

fragments [123]. Acrylophenone can also be transformed to five- or six-membered heterocycles by addition of reagents with double nucleophilic groups such as hydrazine, hydroxylamine, urea and thiourea [124]. Guiding by the same strategy, propiophenone fragments can be converted into various types of heterocycles including imidazole, thiazole and piperazine [125].

\subsubsection{Rapid derivatization strategies of acetophenone fragment}

$\alpha$-Functionalization of acetophenone fragment is an important way to produce a great diversity of derivatives. However, introduction of most functional groups such as hydroxyl and amino by traditional strategies required multiple steps, which caused low yield and efficiency. In recent years, lots of one-step strategies have been developed. Some of them seemed to be practicable for the derivatization of natural phenols (Scheme 14). Direct $\alpha$-amination was completed by the catalysis of copper bromide in an atmosphere of air, but the substrates were restricted to secondary amines [126]. A transition-metalfree $\alpha$-amination strategy employed ammonium iodide as catalyst and sodium percarbonate as oxidant, and the scope of amine was extended to primary amine [127]. There are a lot of research on direct $\alpha$-hydroxylation of acetophenone fragment. Amongst them, the most practical strategy is employing dimethyl sulfoxide as oxidant and catalytic amount of halogenous reagents such as iodine and $N$-bromosuccinimide $[128,129]$. Single isomer of $\alpha$-hydroxyl acetophenone derivatives could be generated in the presence of chiral bimetallic palladium(II) complex [130]. Direct $\alpha$-acetoxylation of acetophenone fragment can be realized by different strategies. A copper-catalyzed system seemed to be an accessible and broad-spectrum way with the substrates ranging from simple carboxylic acid to cinnamic acid derivatives [131]. Catalyzed by $\mathrm{Bu}_{4} \mathrm{NI}, \alpha$-acetoxylation can be accomplished from alcohols [132]. Direct $\alpha$-alkoxylation can be activated by catalytic amount of sodium iodide with $m$-CPBA as the oxidant and para-nitrobenzenesulfonic acid $(\mathrm{NsOH})$ as the additive [133].

\section{Structural derivatization strategies of natural phenols by total-synthesis}

Semi-synthesis strategies will rapidly expand the molecular library from natural phenols, but hardly change the skeleton, and are unaccessible for those natural phenols with rare sources. Total-synthesis is a significant supplement for diversity-oriented derivatization, as it will not be limited by the natural skeleton and sources. Take resveratrol as an example, total-synthesis strategy could produce its monohydroxy, dihydroxy and trans derivatives, which are unachievable for semi-synthesis. Herein, the classical and advanced total-synthesis strategies of typical natural phenol fragments were reviewed, which include stilbenes, chalcones, flavonoids and complex natural phenols.

\subsection{Total-synthesis strategies of stilbene derivatives}

Stilbenes are a class of compounds with a nucleus of diphenylethene or its polymer, which are mostly contained in the xylem of plants. When plants are subject to pests or external stimuli, the content of stilbenes in the stimulated parts will increase significantly. The most common strategies to artificially synthesize stilbene fragments are Wittig reaction [134] and Wittig-Horner reaction [135] of phosphorus ylide with various substituted benzaldehyde (Scheme 15a). Phosphorus ylide can be 
(a) Wittig reaction or Wittig-Horner reaction

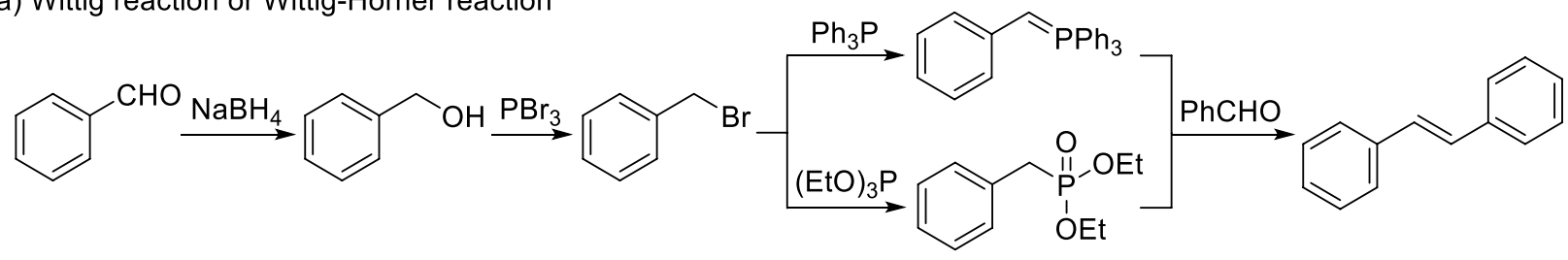

(b) Heck coupling reaction

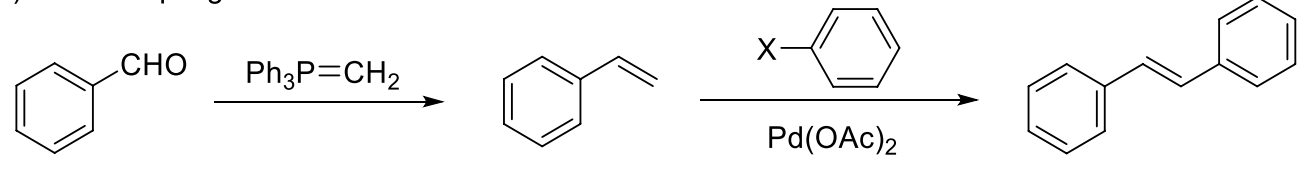

(c) Grignard reaction followed with dehydration

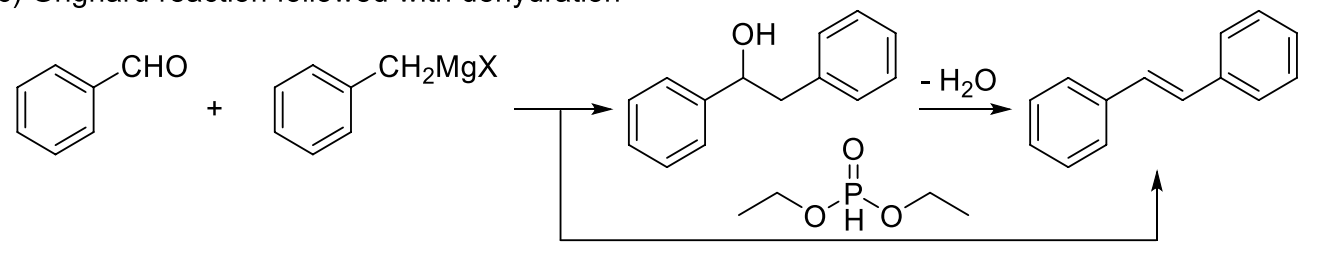

(d) Perkin reaction followed with decarboxylation

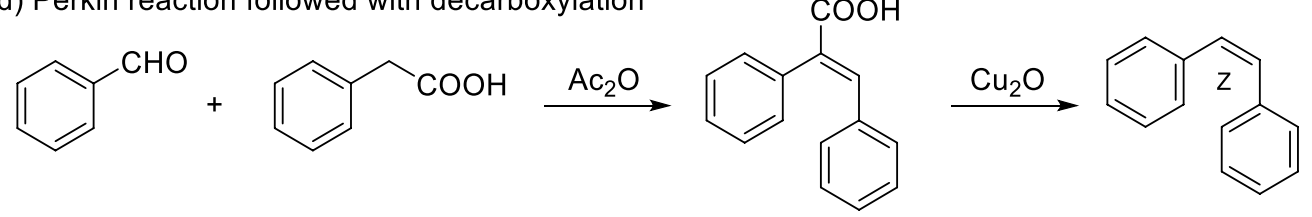

(e) Condensation of aniline and benzaldehyde

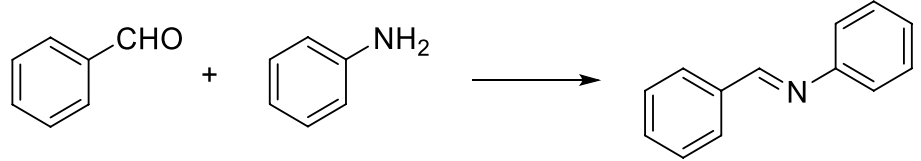

Scheme 15 Total synthesis strategies of stilbene fragments

produced by the reaction of benzyl bromide, which was provided from corresponding benzaldehyde through reduction and bromination, with triphenylphosphine or triethyl phosphite, respectively. Common synthetic methods of stilbenes also include Heck coupling reaction, in which stilbenes were produced by substituted vinylbenzene and phenylhalide in the presence of palladium catalyst [136] (Scheme 15b). Substituted vinylbenzene can be furnished by Wittig reaction from corresponding benzaldehyde. As a highly stereoselective reaction, Heck coupling could give the product of single transconfiguration. Grignard reaction followed with dehydration was another common approach to obtain stilbenes $[137,138]$ (Scheme 15c). In the presence of diethyl phosphite, benzyl magnesium halide and benzaldehyde could directly convert to stilbene [139]. As a kind of natural isomers, cis-stilbenes can be obtained by a two-step synthesis (Scheme 15d). At first, Perkin reaction of aromatic aldehyde and phenylacetic acid yielded an intermediate of carboxyl stilbene [140]. cis-Stilbene was then obtained by removing the carboxyl of the intermediate [141]. In addition, condensation of substituted aniline and benzaldehyde will easily generate Schiff-base type stilbenes [142] (Scheme 15e).

\subsection{Total-synthesis strategies of chalcone derivatives}

Chalcones not only exist extensively in plant as the precursor of flavonoid, but also can be easily obtained by various total-synthesis strategies. Several chalcone derivatives have already been developed as clinical drugs such as Sofalcone and Metochalcone [14]. The most classical total-synthesis strategy of chalcone fragments is aldol condensation of substituted acetophenone and benzaldehyde in the presence of alkali, which might cause the disproportionation (Cannizzaro reaction) of benzaldehyde and secondary reaction of Michael addition 
(a) Aldol condensation

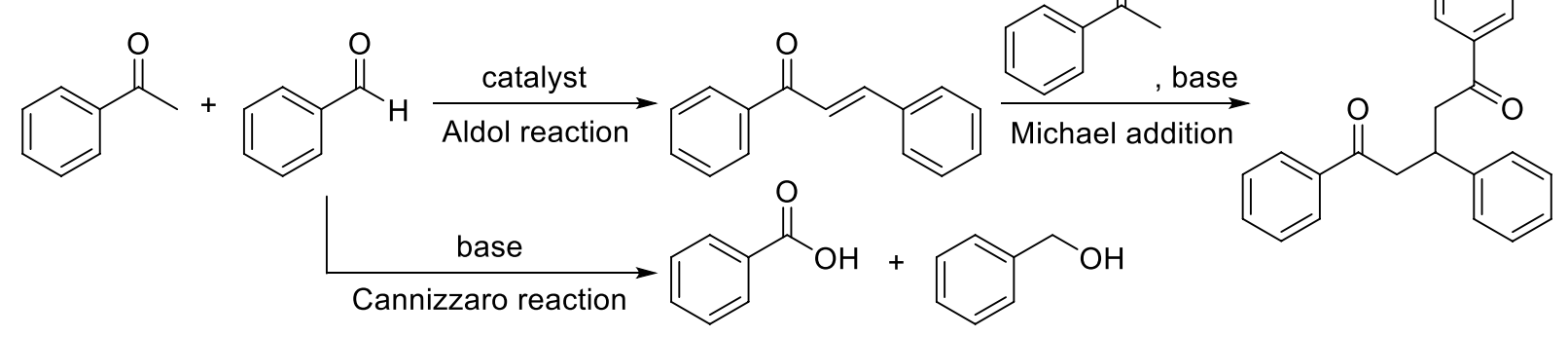

(b) Cross-coupling strategy

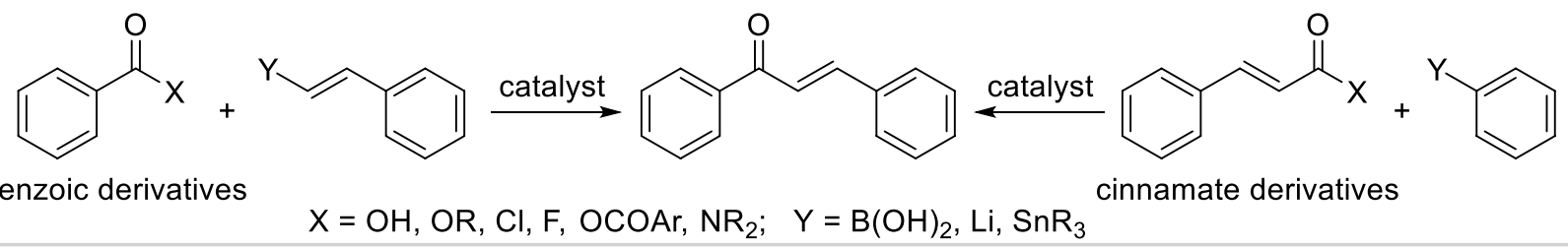

(c) Friedel-Crafts acylation

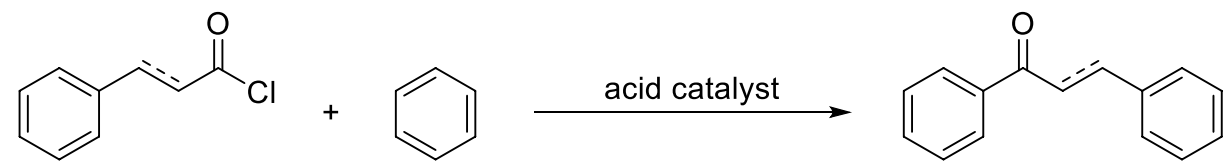

cinnamoyl chloride derivatives

(d) Dehydrogenation of diarylpropenols

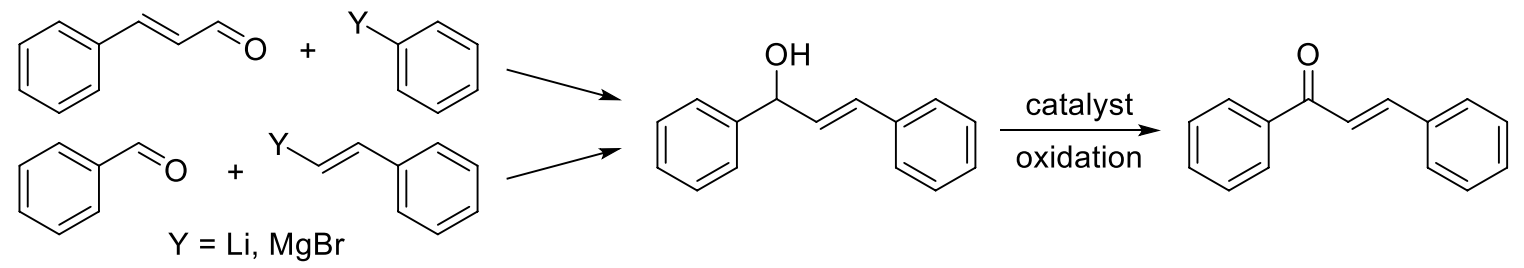

(e) Catalytic alkylation of ketones

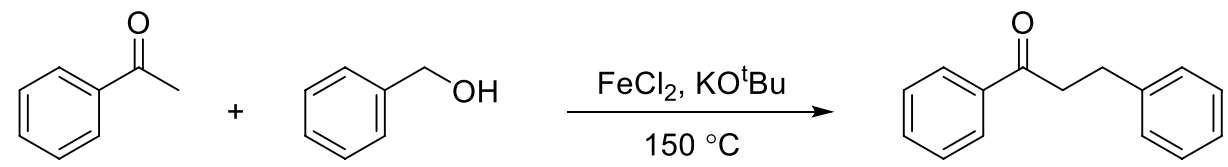

Scheme 16 Total-synthesis strategies of chalcone fragments

(Scheme 16a) [143, 144]. For improving the selectivity and yield of aldol condensation, current researches mainly focus on novel reaction conditions such as microwave [145] and ultrasound [146] and developing novel catalysts. Traditional basic catalysts were replaced by organic base [147] and solid superbase [148] which realized higher selectivity and yield. A variety of acid catalysts including hydrochloric acid [149], para-toluenesulfonic acid [150] and Lewis acids [151,152] were also applied, especially suitable for the aromatic aldehydes with phenolic hydroxyls. Chalcones can also be produced through cross-coupling reaction of benzoic or cinnamate derivatives with organoboron or organometallic compounds mainly including arylboronic acids, aryllithium and arylstannanes catalyzed by transition metal catalysts [153-155] (Scheme 16b). Compared with the good performance and wide application of organoboron, organometallic compounds were rarely used anymore as the reactants of chalcone. Friedel-Crafts acylation of substituted benzene with cinnamoyl chloride derivatives is also a common strategy for total-synthesis of chalcone fragments using protonic or Lewis acid as the catalyst [156] 


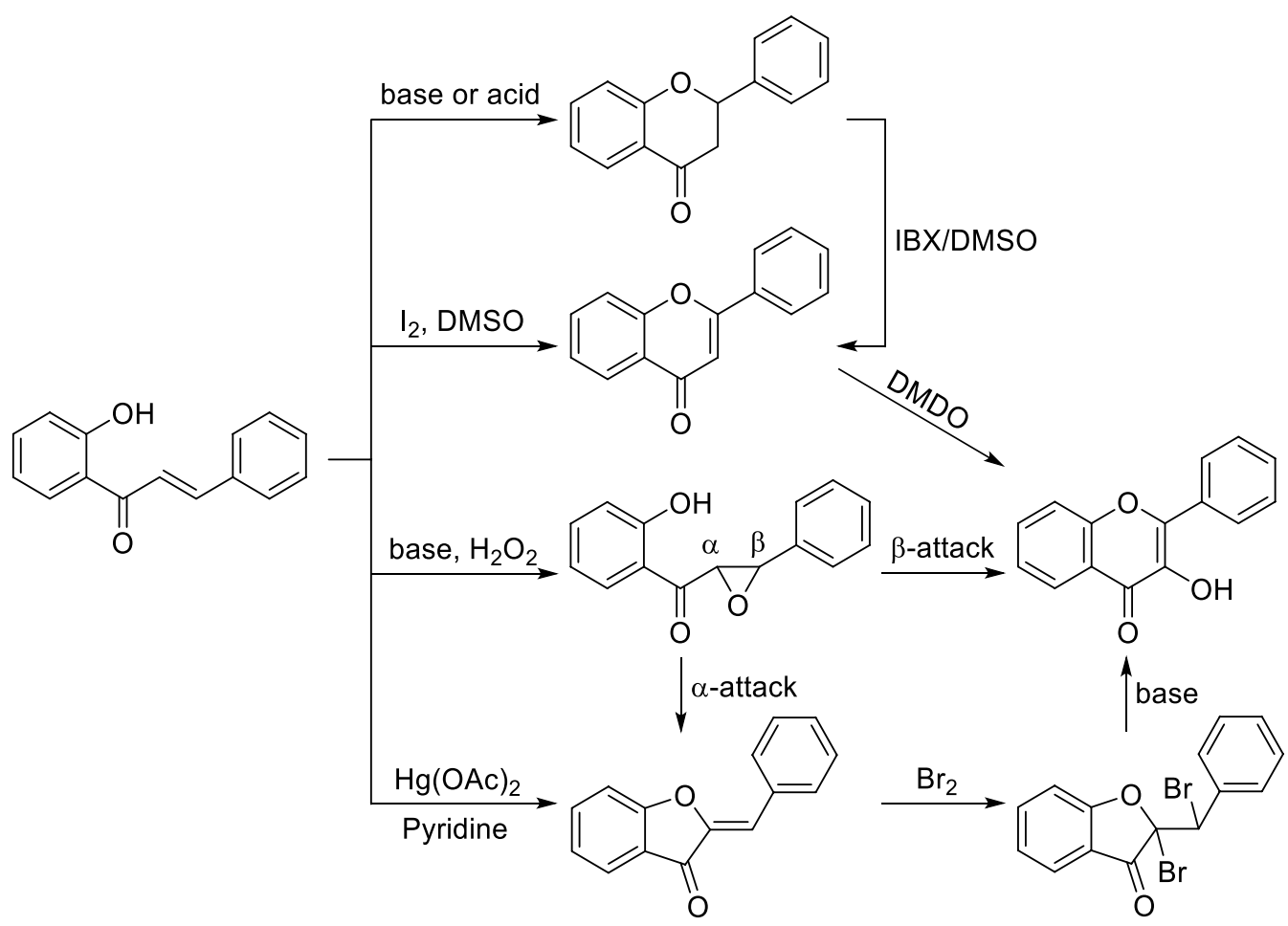

Scheme 17 Total-synthetic strategies of flavonoids by cyclization of 2'-hydroxychalcones

(Scheme 16c). By the same way dihydrochalcones can be provided from phenylpropionyl chloride. Dehydrogenation of diarylpropenols is another strategy to generate chalcone derivatives (Scheme 16d). It always occurred in the presence of manganese dioxide [157], pyridinium chlorochromate (PCC) [158] or transition-metal catalysts [159], which was recently replaced by metal-free oxidations such as $\mathrm{CO}_{2}$ catalytic system [160], owing to their easy separation, low toxicity and cheaper price. Diarylpropenols, the precursor of chalcones, can be obtained by cross coupling of aldehyde with organolithium [161] or Grignard reagent [162] (Scheme 16d). As another reduction state of chalcone, dihydrochalcone was always obtained by catalytic hydrogenation of chalcone, while it can also be directly synthesized by catalytic alkylation of ketones. Recently, a ligand-free alkylation of ketones with primary alcohols was developed using $\mathrm{FeCl}_{2}$ as the catalyst (Scheme 16e), exhibiting a wide application prospect in rapid synthesis of dihydrochalcones [163].

\subsection{Total-synthesis strategies of flavonoid derivatives}

Flavonoids are a large class of polyphenol widely distributed in natural vegetation with a $\mathrm{C} 6-\mathrm{C} 3-\mathrm{C} 6$ backbone. Depending on the structures, flavonoids can be categorized as flavone, flavanone (dihydroflavone), flavonol, isoflavone, aurone and so on. Cyclization of 2'-hydroxychalcones was a universal strategy to synthesize different types of flavonoids (Scheme 17). Amongst them, flavanone could be easily obtained by cyclization of 2'-hydroxychalcones under the catalysis of alkali or acid. [164, 165] Oxidation of flavanone by IBX/DMSO system will generate flavones, while catalytic hydrogenation could transform flavones back to flavanone. Flavones can also be produced by oxidative cyclization of 2'-hydroxychalcones, occurring in the presence of iodine with the solvent of dimethyl sulfoxide [166, 167]. Triethylene Glycol (TEG) was a common alternative solvent, might leading to higher yield for specific flavones $[168,169]$. However, excess iodine and reaction time will give rise to the formation of 3-iodoflavones [170], while novel iodine sources such as iodine monochloride [171] and ammonium iodide [172] have been developed to solve this problem. In a water-mediated phosphorylative cyclodehydrogenation, flavones and flavanones can be synthesized in the same condition with the product type controlled by dosage of reagent [173]. As the oxidative state of flavones, flavonols can be produced from flavones by the oxidation with 3,3-dimethyldioxirane (DMDO) [174] or Algar-Flynn-Oyamada reaction in the presence of base and hydrogen peroxide [175, 176], which may generate by-product of aurone due to the different attacking position of epoxide [177]. Selective synthesis of 
(a) Two-step synthesis of flavones

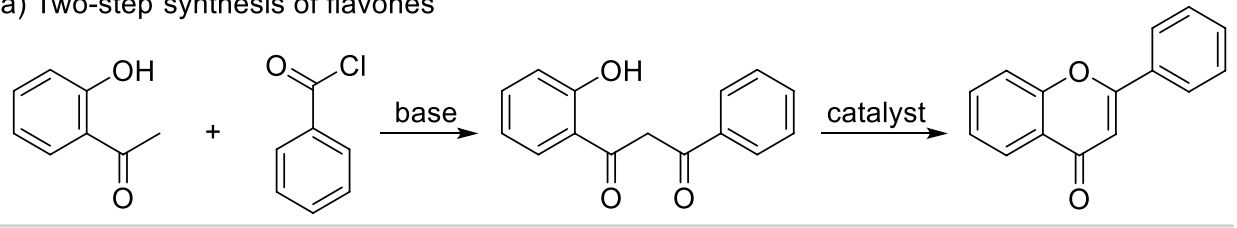

(b) Microwave-aided synthesis of flavones<smiles>CCOC(=O)CC(=O)c1ccccc1</smiles>

(c) One-pot synthesis of flavones<smiles>C#Cc1ccccc1</smiles>

(d) Mannich-type reaction to synthesize flavanones<smiles>C[C+](Cc1ccccc1)c1ccccc1C=O</smiles>

(e) Claisen-Schmidt reaction to synthesize aurone derivatives<smiles>[X]c1[X]c2ccccc2c(=O)c(=O)c1</smiles>

(f) Catalyst-controlled selective synthesis of flavones and aurones

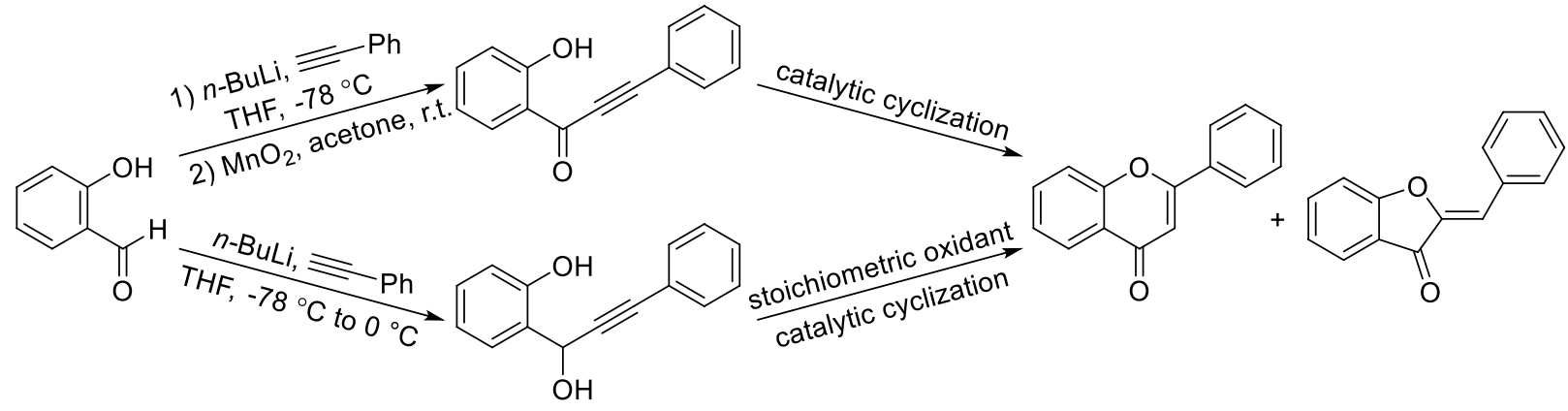

Scheme 18 Rapid and novel synthetic strategies of flavones and aurones

aurone could be achieved through oxidative cyclization of 2'-hydroxychalcones mediated by $\mathrm{Hg}(\mathrm{OAc})_{2}$ in a good yield $[178,179]$. Aurones can also be converted to flavonols by bromination, elimination and rearrangement, which was known as Auwers synthesis [180].

Classical synthetic methods of flavonoids were limited by the preparation of 2'-hydroxychalcones. Nowadays, novel and rapid synthetic strategies of flavonoids have been developed and gradually replaced the classical methods. Two-step synthesis from 2-hydroxyacetone and benzoyl chloride has been the most common strategy to generate flavones (Scheme 18a) due to its excellent applicability and convenience [181-183]. Firstly, $\beta$-propanedione were synthesized from 2-hydroxyacetone and benzoyl chloride via esterification and basemediated Baker-Venkataraman rearrangement. Secondly, 
(a) Vilsmeier-Haack reaction

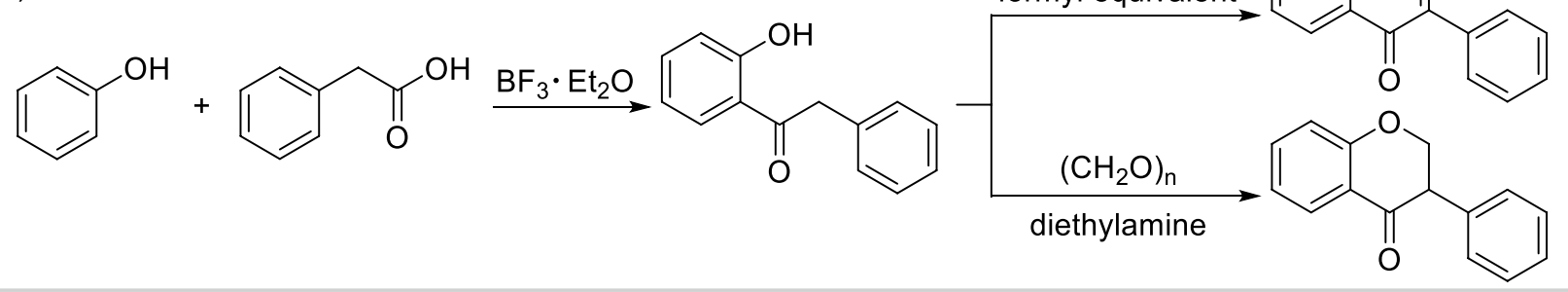

(b) Three-steps strategy<smiles>CC(=O)c1ccccc1O</smiles>

Scheme 19 Total-synthetic strategies of isoflavones

cyclization of $\beta$-propanedione generated flavones. Addition of phase transfer catalysts such as tetrabutylammonium hydrosulfate could make 2 steps in one-pot [184]. It's also reported flavones were synthesized directly from $\beta$-ketoester and phenol by microwave irradiation under eco-friendly solvent-free conditions in a high yield [185] (Scheme 18b). Under dual catalysis of $\mathrm{FeCl}_{3}$ and piperidine, flavones could also be directly supplied from salicylaldehyde derivatives and substituted phenylacetylenes with atmospheric oxygen as the stoichiometric oxidant [186] (Scheme 18c). As the reduction state of flavones, flavanones could be directly synthesized from 2-hydroxyacetophenone and benzaldehyde by the catalysis of aniline via Mannich-type reaction [187, 188] (Scheme 18d). In addition to the cyclization of 2'-hydroxychalcones which is presented in Scheme 17, aurone and its derivatives can be easily synthesized by Claisen-Schmidt reaction of aromatic aldehyde with benzofuranone derivative [189] (Scheme 18e). Over the last decade, a novel approach was developed to efficiently prepare flavones and aurones from $o$-alkynoylphenols (Scheme 18f), while the product types were determined by catalytic system. Employing trifluoroacetic acid or dimethylaminopyridine as the catalyst regioselectively promoted the generation of flavones [190]. Using tributylphosphine [191] or alkali salt such as cesium carbonate [192] mainly produced aurones. As the intermediate, $o$-alkynoylphenols can be synthesized by cross-coupling of salicylaldehyde derivatives with alkynyl benzene [193]. Similarly, flavones and aurones can be synthesized from o-hydroxylpropinyl phenols, the reduzate of $o$-alkynoylphenols, through stoichiometric oxidation and catalytic cycliczation [194, 195].
Isoflavones were always directly synthesized by Vilsmeier-Haack reaction of deoxybenzoin with formyl equivalent such as methylsulfonyl chloride and DMF [196, 197] (Scheme 19a). Base catalyzed condensation of deoxybenzoin with paraformaldehyde will provide isoflavanone [119], which can be promoted by Microwave [198]. The deoxybenzoin intermediate was always supplied by a Friedel-Crafts acylation of phenol and phenylacetic acid derivatives. Isoflavones can also be synthesized by a three-step strategy (Scheme 19b). Firstly, the intermediate was synthesized through the condensation of $o$-hydroxy acetophenone with DMF. Then it was cyclized under the action of iodine to generate 3-iodochromone [199]. Isoflavones were finally obtained by the cross-coupling of 3-iodochromones with arylboronic acids [200].

\subsection{Total-synthesis strategies of complex natural phenol derivatives}

Total-synthesis of complex natural phenols was still a challenge due to the regioselectivity of multi-reactive sites and the enantioselectivity of multi-chiral centers, especially for non-symmetrical polyphenols. For symmetric natural polyphenols (i.e., the polymers of simple phenols), the general total-synthesis strategy can be summarized as synthesis of simple phenol and then coupling. Chemo- and regio-selective reactions including the protection/deprotection of hydroxyl groups were required which have been discussed above. As a solution to control the stereochemistry, the configuration of alcohol hydroxyl groups can be reversed by dehydrogenation and selective reduction. For instance, dehydrogenation with Dess-Martin periodinane (DMP) followed by 


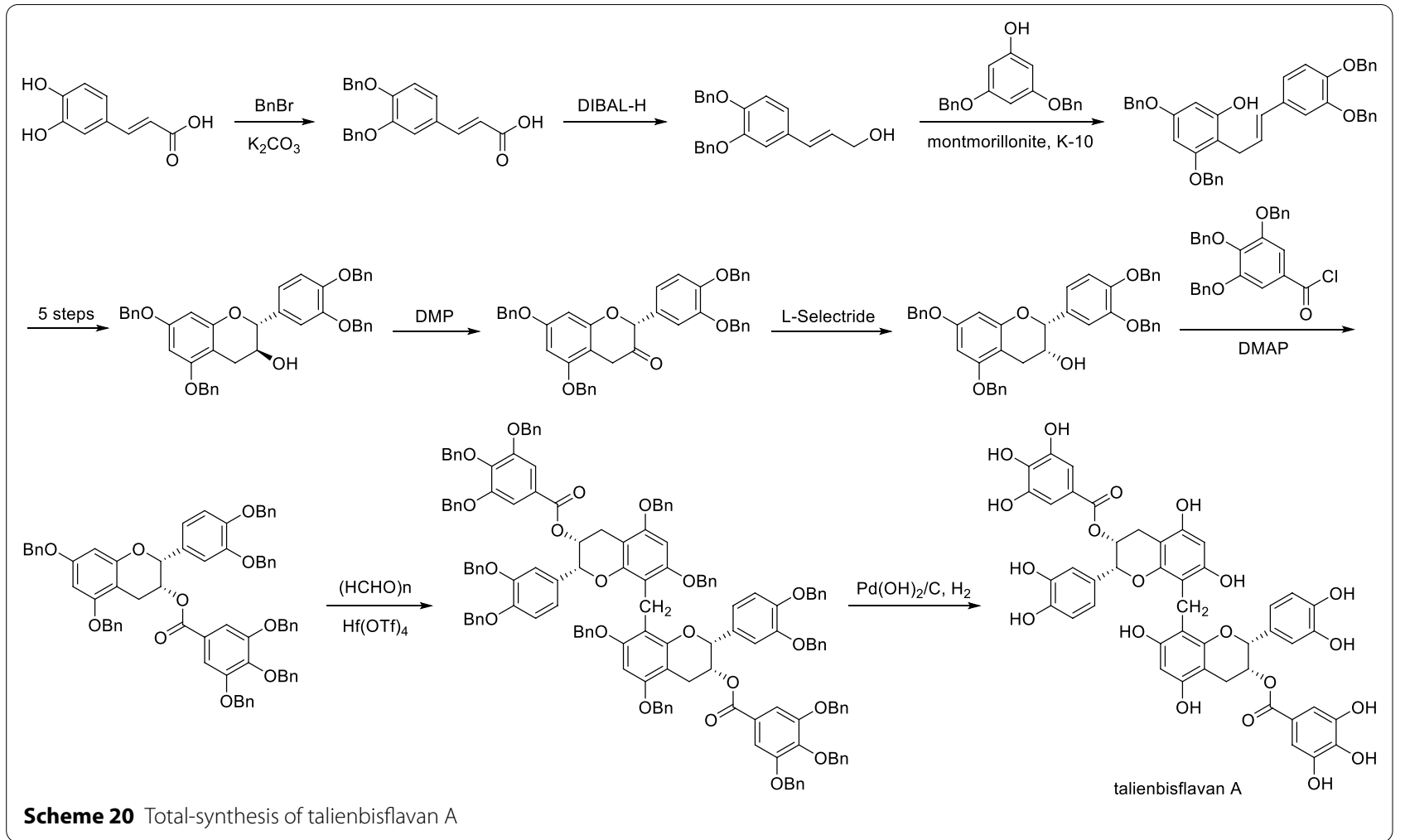

reduction with L-selectride provided exclusively the cissubstituted talienbisflavan A [201] (Scheme 20).

Besides the coupling of simple phenol by methylene in above example, symmetric natural polyphenols were always directly coupled by regioselective oxidation. In the biosynthetic process of gossypol, a complicated natural polyphenol, it was dimerized from hemigossypol by peroxidase in the presence of dirigent protein that controlled the enantiomeric ratio of product [202] (Scheme 21). Inspired by the biosynthetic process, hemigossypol was also pre-synthesized in the artificial total-synthetic process of gossypol, and then coupled by an enzyme-free peroxide system [203]. Although the coupling strategies of phenol units can be referenced, the preparations of phenol units are totally individualized for different products. The construction of $\mathrm{C}-\mathrm{O}$ bond on benzene ring with high selectivity and efficiency was the key challenge.

\section{Conclusions and perspectives}

As described in this review, a great abundance of strategies can be applied in the derivatization of natural phenols, including semi-synthesis strategies based on common fragments and total-synthesis schemes of typical natural phenols. In the section of semi-synthesis, almost all classical strategies have been covered, which are preferred in initial trial period as they can rapidly construct the molecular library of derivatives. Those regioselective strategies are particularly suited for complex natural phenols with multiple reactive centers, while diastereoselective strategies could promote the generation of single enantiomer products as the conformation have a significant influence on biological activity. Total-synthesis strategies are suggested for natural phenols with rare resources. More importantly, they can avoid the limitation of original skeleton, which provide the possibility for diversity-oriented derivatization.

Unlike previous reviews analyzing how to design bioactive structures, this review focuses on providing available options of structural derivatization as diverse as possible, which will mediately help inspire the ideas of structure design. Researchers still need to select from these options according to their interests combined with drug design theory and technology. Due to the great variety of chemical reaction conditions and the limitation of space, only the common conditions were listed in this review. As referred in the review, some reactions have already been discussed systematically and separately in previous reports. In addition, it's still a challenge to formulate total-synthesis schemes for novel and complex natural phenols, as there is no unified total-synthesis strategy for different types of natural phenols. Researchers also need consider whether there are reactive groups requiring protection before applying these strategies, while selective protection 

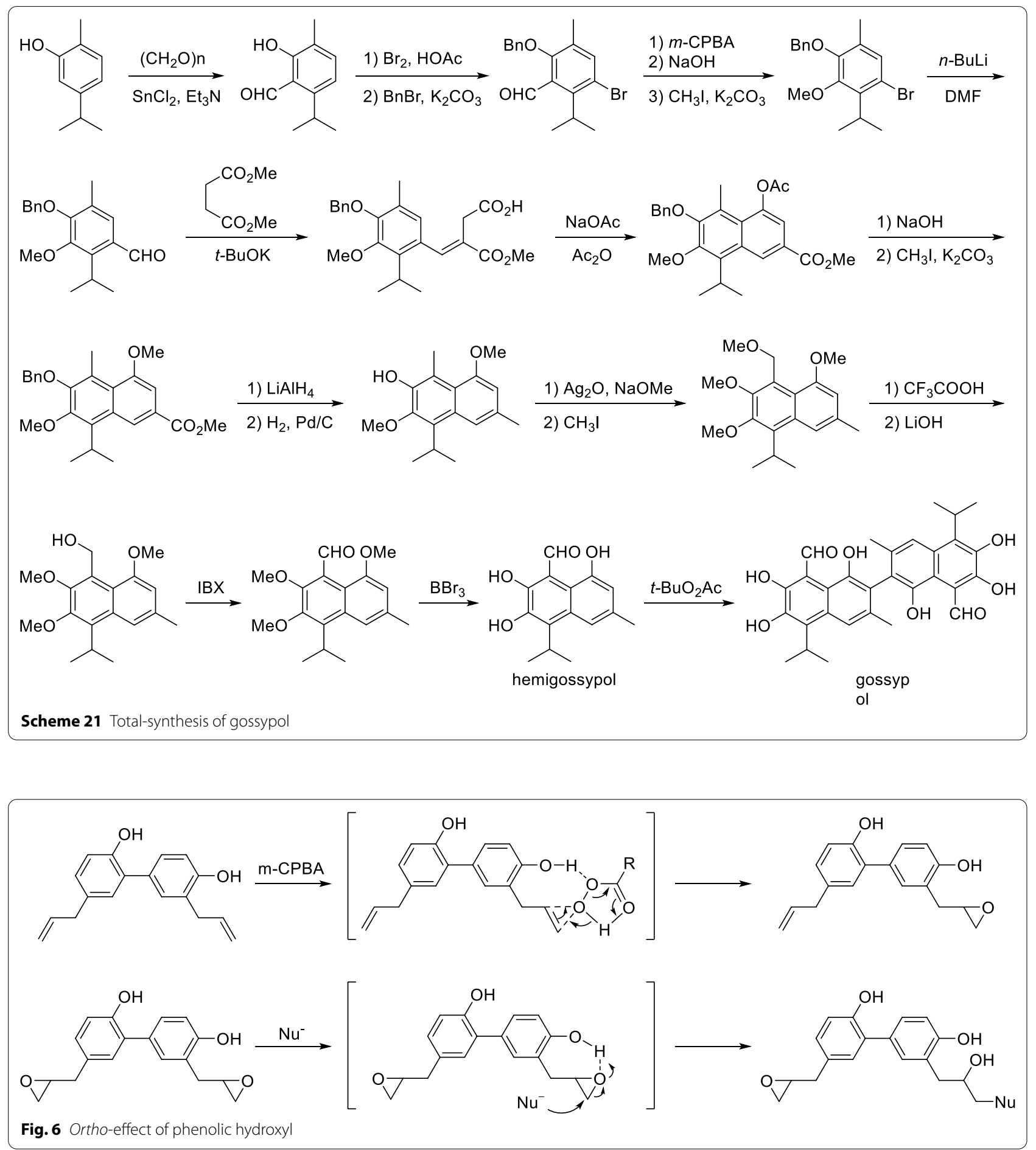

and deprotection strategies for phenolic hydroxyls have been discussed in the review.

Natural products play an irreplaceable role in drug research and development, as they are structurally complementary to synthetic compounds. However, with the decrease of newly discovered natural compounds, especially from land surface, the research hotspot has gradually transformed from traditional discovery and isolation into in-depth and secondary development. In the meantime, the emergence and development of high-throughput-screening technologies have significantly improved the efficiency of bioactivity screening, 
(a) Antifungal activity (MIC) of emodin and its derivative against Schizosaccharomyces pombe:<smiles>Cc1cc(O)c2c(c1)C(=O)c1cc(O)cc(O)c1C2=O</smiles><smiles>C=C=C</smiles>

$1300 \mu \mathrm{M}$

$97.6 \mu \mathrm{M}$

(b) $\mathrm{DPPH}$ radical scavenging ability $\left(E \mathrm{E}_{50}\right)$ of isoflavone derivatives:<smiles>COc1cc2occ(-c3ccc(O)cc3)c(=O)c2cc1O</smiles><smiles>C=C=C=[W]</smiles>

(c) Inhibition activity $\left(\mathrm{IC}_{50}\right)$ of chalcone derivatives against Pim-1 Kinase:<smiles>COc1ccc(/C=C/C(=O)c2ccccc2)cc1</smiles><smiles>C=CCO[Na]</smiles>

Fig. 7 Bioactivity of natural phenols and their analogues derived from modifying phenylketone fragments

leading to greater demand of the derivative quantity and diversity. Structural derivatization is one of the most important way to continuously develop the potentialities of existing natural compounds, and meanwhile provide more samples for high-throughput-screening. Description in this review will help to take full advantage of classical and advanced strategies, break the barrier between the fields of natural phenols and chemical synthesis, and inspire the design of derivative structures. Currently, increasing organic reactions and biocatalytic reactions were developed [204], as well as synthetic biology which can realize the bio-derivatization [205]. Application of novel techniques will supply more chances and diversity for structural derivatization of natural phenols.

\section{Acknowledgements}

This review was supported by National Training Program of Innovation and Entrepreneurship for Undergraduates (202101341012) and Talent Startup Project of Zhejiang A \& F University Scientific Research and Development Fund (2034020154).

\section{Authors' contributions}

DL drafted and revised the manuscript. SJ drafted the section of total-synthesis and contributed significantly to manuscript preparation. AZ participated in the revision of manuscript. TW improved the figures and shemes. YQ provided guidance for the composition and expression. QS contributed to the conception of this review. All authors read and approved the final manuscript.

\section{Funding}

National Training Program of Innovation and Entrepreneurship for Undergraduates (202101341012) Senze Jiang, Talent Startup Project of Zhejiang A \& F

University Scientific Research and Development Fund (2034020154) Ding Lin.

\section{Declarations}

Competing interests

There are no conflicts of interest to declare.

\section{Author details}

${ }^{1}$ State Key Laboratory of Subtropical Silviculture, Zhejiang A \& F University, Hangzhou 311300, China. ${ }^{2}$ Zhejiang Provincial Key Laboratory of Resources Protection and Innovation of Traditional Chinese Medicine, Zhejiang A \& F University, Hangzhou 311300, China.

Received: 29 December 2021 Accepted: 15 February 2022

Published online: 07 March 2022

\section{References}

1. Chen L, Teng H, Xie Z, Cao H, Cheang WS, Skalicka-Woniak K, Georgiev MI, Xiao J. Modifications of dietary flavonoids towards improved bioactivity: an update on structure-activity relationship. Crit Rev Food Sci Nutr. 2018;58:513-27.

2. Zhou Y, Zheng J, Li Y, Xu DP, Li S, Chen YM, Li HB. Natural polyphenols for prevention and treatment of cancer. Nutrients. 2016;8:515.

3. Mehmood A, Usman M, Patil P, Zhao L, Wang C. A review on management of cardiovascular diseases by olive polyphenols. Food Sci Nutr. 2020;8:4639-55.

4. Caruana M, Vassallo N. Tea polyphenols in Parkinson's disease. Adv Exp Med Biol. 2015;863:117-37. 
5. Ho L, Pasinetti GM. Polyphenolic compounds for treating neurodegenerative disorders involving protein misfolding. Expert Rev Proteomics. 2010;7:579-89.

6. Yu JS, Park M, Pang C, Rashan L, Jung WH, Kim KH. Antifungal phenols from Woodfordia uniflora collected in Oman. J Nat Prod. 2020;83:2261-8.

7. Silva RFM, Pogacnik L. Polyphenols from food and natural products: neuroprotection and safety. Antioxidants. 2020;9:61.

8. Mastinu A, Ribaudo G, Ongaro A, Bonini SA, Memo M, Gianoncelli A. Critical review on the chemical aspects of cannabidiol (cbd) and harmonization of computational bioactivity data. Curr Med Chem. 2021;28:213-37.

9. Srinivasan K. Biological activities of red pepper (capsicum annuum) and its pungent principle capsaicin: a review. Crit Rev Food Sci Nutr. 2016;56:1488-500.

10. Zhang Y, Qin L, Xie J, Li J, Wang C. Eupatilin prevents behavioral deficits and dopaminergic neuron degeneration in a Parkinson's disease mouse model. Life Sci. 2020;253: 117745.

11. Bi YL, Min M, Shen W, Liu Y. Genistein induced anticancer effects on pancreatic cancer cell lines involves mitochondrial apoptosis, G0/G1 cell cycle arrest and regulation of STAT3 signalling pathway. Phytomedicine. 2018;39:10-6.

12. Wilson BAP, Thornburg CC, Henrich CJ, Grkovic T, O'Keefe BR. Creating and screening natural product libraries. Nat Prod Rep. 2020:37:893-918.

13. Serrya MS, El-Sheakh AR, Makled MN. Evaluation of the therapeutic effects of mycophenolate mofetil targeting Nrf-2 and NLRP3 inflammasome in acetic acid induced ulcerative colitis in rats. Life Sci. 2021:271: 119154.

14. Gao F, Huang G, Xiao J. Chalcone hybrids as potential anticance agents: current development, mechanism of action, and structureactivity relationship. Med Res Rev. 2020:40:2049-84.

15. Piska K, Koczurkiewicz P, Bucki A, Wojcik-Pszczola K, Kolaczkowski M, Pekala E. Metabolic carbonyl reduction of anthracyclines-role in cardiotoxicity and cancer resistance. Reducing enzymes as putative targets for novel cardioprotective and chemosensitizing agents. Invest New Drugs. 2017;35:375-85.

16. Grisoni F, Merk D, Consonni V, Hiss JA, Tagliabue SG, Todeschini R, Schneider $\mathrm{G}$. Scaffold hopping from natural products to synthetic mimetics by holistic molecular similarity. Commun Chem. 2018;1:44.

17. Wang S, Dong G, Sheng C. Structural simplification of natural products. Chem Rev. 2019;119:4180-220.

18. Guo Z. The modification of natural products for medical use. Acta Pharm Sin B. 2017;7:119-36.

19. Liu R, Li X, Lam KS. Combinatorial chemistry in drug discovery. Curr Opin Chem Biol. 2017;38:117-26.

20. Berthet J, Agouridas L, Chen S, Allouchi H, Melnyk P, Champagne B, Delbaere $S$. Synthesis and switching properties of new derivatives of azoresveratrol. Dyes Pigments. 2019;171: 107666.

21. Zacharias NM, Ornelas A, Lee J, Hu J, Davis JS, Uddin N, Pudakalakatti S, Menter DG, Karam JA, Wood CG, et al. Real-time interrogation of aspirin reactivity, biochemistry, and biodistribution by hyperpolarized magnetic resonance spectroscopy. Angew Chem Int Ed Engl. 2019:58:4179-83.

22. Penalver P, Belmonte-Reche E, Adan N, Caro M, Mateos-Martin ML, Delgado M, Gonzalez-Rey E, Morales JC. Alkylated resveratrol prodrugs and metabolites as potential therapeutics for neurodegenerative diseases. Eur J Med Chem. 2018:146:123-38

23. Hassan F, Kawamoto M, Salikolimi K, Hashizume D, Hirose T, Ito Y. Onepot heterocyclic ring closure of 1,1'-bi-2-naphthol to $7 \mathrm{H}$-dibenzo[c, g] carbazole. Tetrahedron Lett. 2018;59:99-102.

24. Jaxel J, Amer H, Bacher M, Roller A, Guggenberger M, Zwirchmayr NS, Hansmann C, Liebner F. Facile synthesis of 1-butylamino- and 1,4-bis(butylamino)-2-alkyl-9,10-anthraquinone dyes for improved supercritical carbon dioxide dyeing. Dyes Pigments. 2020;173: 107991

25. Labadie SS, Li J, Blake RA, Chang JH, Goodacre S, Hartman SJ, Liang W, Kiefer JR, Kleinheinz T, Lai T. Discovery of a C-8 hydroxychromene as a potent degrader of estrogen receptor alpha with improved rat oral exposure over GDC-0927. Bioorg Med Chem Lett. 2019;29:2090-3.

26. Yu J, Zhang P, Wu J, Shang Z. Metal-free C-N bond-forming reaction: straightforward synthesis of anilines, through cleavage of aryl C-O bond and amide C-N bond. Tetrahedron Lett. 2013;54:3167-70.
27. Crosby IT, Shin JK, Capuano B. The application of the schmidt reaction and beckmann rearrangement to the synthesis of bicyclic lactams: some mechanistic considerations. Aust J Chem. 2010;63:211-26.

28. Beria I, Ballinari D, Bertrand JA, Borghi D, Bossi RT, Brasca MG, Cappella P, Caruso M, Ceccarelli W, Ciavolella A. Identification of 4,5-dihydro$1 \mathrm{H}$-pyrazolo[4,3-h]quinazoline derivatives as a new class of orally and selective Polo-like kinase 1 inhibitors. J Med Chem. 2010;53:3532-51.

29. Wu J, Yu J, Wang Y, Zhang P. Direct amination of phenols under metalfree conditions. Synlett. 2013;24:1448-54.

30. Maguire CJ, Carlson GJ, Ford JW, Strecker TE, Hamel E, Trawick ML, Pinney KG. Synthesis and biological evaluation of structurally diverse alpha-conformationally restricted chalcones and related analogues. Medchemcomm. 2019;10:1445-56.

31. Maltais R, Poirier D. Development of a gram-scale synthesis of pbrm, an irreversible inhibitor of $17 \beta$-hydroxysteroid dehydrogenase type 1. Org Process Res Dev. 2019;23:2323-35.

32. Boutard N, Bialas A, Sabiniarz A, Guzik P, Banaszak K, Biela A, Bien M, Buda A, Bugaj B, Cieluch E, et al. Discovery and structure-activity relationships of $\mathrm{N}$-aryl 6-aminoquinoxalines as potent pfkfb3 kinase inhibitors. ChemMedChem. 2019;14:169-81.

33. Liu Y, Liang Y, Jiang J, Qin Q, Wang L, Liu X. Design, synthesis and biological evaluation of 1,4-dihydroxyanthraquinone derivatives as anticancer agents. Bioorg Med Chem Lett. 2019;29:1120-6.

34. Sagrera G, Bertucci A, Vazquez A, Seoane G. Synthesis and antifungal activities of natural and synthetic biflavonoids. Bioorg Med Chem. 2011;19:3060-73.

35. Park J-Y, Kim S-W, Park H-J, Im W-B, Lee J-K, Yoon S-H. Synthesis and antioxidant effect of caffeic acid analogues bearing a carboxy and hydroxymethyl group. Bull Korean Chem Soc. 2010;31:3860-3.

36. Tomanik M, Economou C, Frischling MC, Xue M, Marks VA, Mercado BQ, Herzon SB. Development of a convergent enantioselective synthetic route to (-)-myrocin g. J Org Chem. 2020;85:8952-89.

37. Barontini M, Bernini R, Crisante F, Fabrizi G. Selective and efficient oxidative modifications of flavonoids with 2-iodoxybenzoic acid (IBX). Tetrahedron. 2010;66:6047-53.

38. Koyani RD, Vazquez-Duhalt R. Enzymatic activation of the emerging drug resveratrol. Appl Biochem Biotechnol. 2017;185:248-56.

39. Hong S, Liu S. Targeted acylation for all the hydroxyls of (+)-catechin and evaluation of their individual contribution to radical scavenging activity. Food Chem. 2016;197:415-21.

40. Jiang Z-Y, Wang Y-G. A mild, efficient and selective deprotection of t-butyldimethylsilyl-protected phenols using cesium carbonate. Tetrahedron Lett. 2003;44:3859-61.

41. Mashima K, Ohshima T, Iwasaki T, Maegawa Y, Hayashi Y. A simple, general, and highly chemoselective acetylation of alcohols using ethyl acetate as the acetyl donor catalyzed by a tetranuclear zinc cluster. Synlett. 2009;2009:1659-63.

42. Miyazawa T, Yamamoto M, Danjo H. Selective acylation of the phenolic hydroxyl of (hydroxyalkyl)phenols by using vinyl carboxylates as acyl donors in the presence of rubidium fluoride. Monatsh Chem Chem Mon. 2013;144:1351-4.

43. Liu HX, Dang YQ, Yuan YF, Xu ZF, Qiu SX, Tan HB. Diacyl disulfide: a reagent for chemoselective acylation of phenols enabled by 4- $(\mathrm{N}$ N-dimethylamino)pyridine catalysis. Org Lett. 2016;18:5584-7.

44. V R. K., A O. J. Partial methylation of quercetin: direct synthesis of tamarixetin, ombuin and ayanin. J Heterocycl Chem. 1976; 13:1293-1295.

45. Jurd L. Plant polyphenols. V. Selective alkylation of the 7-hydroxyl group in polyhydroxyflavones. J Am Chem Soc. 1958;80:5531-6.

46. Jurd L. The selective alkylation of polyphenols. II. Methylation of 7-, 4'-, and 3'-hydroxyl groups in flavonols. J Org Chem. 1962;27:1294-7.

47. Li NG, Shi ZH, Tang YP, Yang JP, Duan JA. An efficient partial synthesis of 4'-O-methylquercetin via regioselective protection and alkylation of quercetin. Beilstein J Org Chem. 2009;5:60.

48. Grynkiewicz G, Zegrocka-Stendel O, Pucko W, Ramza J, Kościelecka A, Kołodziejski W, Woźniak K. X-ray and 13C CP MAS investigations of structure of two genistein derivatives. J Mol Struct. 2004;694:121-9.

49. Szeja W, Puchałka J, Świerk P, Hendrich AB, Grynkiewicz G. Selective alkylation of genistein and daidzein. Chem Biol Interface. 2013;3:95-106.

50. Dai JL, Shao NQ, Zhang J, Jia RP, Wang DH. Cu(II)-catalyzed ortho-selective aminomethylation of phenols. J Am Chem Soc. 2017;139:12390-3. 
51. Shao NQ, Yao ZL, Wang DH. Cu(II)-catalyzed ortho-selective amination of simple phenols with o-benzoylhydroxylamines. Isr J Chem. 2020;60:429-32.

52. Qian X, Han J, Wang L. Copper-catalyzed selective ortho-arylations of 2-naphthol and phenol derivatives with diaryliodonium salts. Tetrahedron Lett. 2016;57:607-10.

53. Xiong $X$, Yeung $Y$-Y. Ammonium salt-catalyzed highly practical orthoselective monohalogenation and phenylselenation of phenols: scope and applications. ACS Catal. 2018;8:4033-43.

54. Ackermann L. Carboxylate-assisted ruthenium-catalyzed alkyne annulations by $\mathrm{C}-\mathrm{H} / \mathrm{Het}-\mathrm{H}$ bond functionalizations. Acc Chem Res. 2014:47:281-95.

55. Reddy MC, Jeganmohan M. Ruthenium-catalyzed selective aerobic oxidativeortho-alkenylation of substituted phenols with alkenes through C-H bond activation. Eur J Org Chem. 2013;2013:1150-7.

56. Kong ZL, Tzeng SC, Liu YC. Cytotoxic neolignans: an SAR study. Bioorg Med Chem Lett. 2005;15:163-6.

57. Fang $\mathrm{Y}-\mathrm{T}$, Lin $\mathrm{C}-\mathrm{N}, \mathrm{Wu} \mathrm{H}-\mathrm{T}$, Lee $\mathrm{Y}$-J. Total synthesis of $( \pm)$-glyflavanone by a rigid quaternary ammonium salt. J Chin Chem Soc. 2007:54:817-22.

58. Joshi BP, Sharma A, Sinha AK. Ultrasound-assisted convenient synthesis of hypolipidemic active natural methoxylated (E)-arylalkenes and arylalkanones. Tetrahedron. 2005;61:3075-80.

59. Hassam M, Taher A, Arnott GE, Green IR, van Otterlo WA. Isomerization of allylbenzenes. Chem Rev. 2015;115:5462-569.

60. Yadav Y, Owens EA, Sharma V, Aneja R, Henary M. Synthesis and evaluation of antiproliferative activity of a novel series of hydroxychavicol analogs. Eur J Med Chem. 2014;75:1-10.

61. Freire RS, Morais SM, Catunda-Junior FE, Pinheiro DC. Synthesis and antioxidant, anti-inflammatory and gastroprotector activities of anethole and related compounds. Bioorg Med Chem. 2005;13:4353-8.

62. Taferner B, Schuehly W, Huefner A, Baburin I, Wiesner K, Ecker GF, Hering S. Modulation of GABAA-receptors by honokiol and derivatives: subtype selectivity and structure-activity relationship. J Med Chem. 2011:54:5349-61.

63. Saikia I, Borah AJ, Phukan P. Use of bromine and bromo-organic compounds in organic synthesis. Chem Rev. 2016;116:6837-7042.

64. Das B, Venkateswarlu K, Damodar K, Suneel K. Ammonium acetate catalyzed improved method for the regioselective conversion of olefins into halohydrins and haloethers at room temperature. J Mol Catal A: Chem. 2007;269:17-21.

65. Galli M, Fletcher CJ, Del Pozo M, Goldup SM. Scalable anti-Markovnikov hydrobromination of aliphatic and aromatic olefins. Org Biomol Chem. 2016;14:5622-6.

66. Maxwell AC, Flanagan SP, Goddard R, Guiry PJ. Rhodium-catalysed hydroboration employing new Quinazolinap ligands: an investigation into electronic effects. Tetrahedron Asymmetry. 2010;21:1458-73.

67. Connolly DJ, Lacey PM, MCCarthy M, Saunders CP, Carroll A-M, Goddard R, Guiry PJ. Preparation and resolution of a modular class of axially chiral quinazoline-containing ligands and their application in asymmetric rhodium-catalyzed olefin hydroboration. J Org Chem. 2004;69:6572-89.

68. McCarthy M, Guiry PJ, Hooper MW. Enantioselective hydroboration of olefins catalysed by cationic rhodium complexes of 2-phenylquinazolin-4-yl-2-(diphenylphosphino)naphthalene. Chem Commun. 2000. https://doi.org/10.1039/b004014m.

69. Deng CM, Ma YF, Wen YM. Transition-metal-free borylation of alkynes and alkenes. ChemistrySelect. 2018;3:1202-4

70. Toribatake K, Nishiyama H. Asymmetric diboration of terminal alkenes with a rhodium catalyst and subsequent oxidation: enantioselective synthesis of optically active 1,2-diols. Angew Chem Int Ed Engl. 2013:52:11011-5.

71. Coombs JR, Haeffner F, Kliman LT, Morken JP. Scope and mechanism of the Pt-catalyzed enantioselective diboration of monosubstituted alkenes. J Am Chem Soc. 2013;135:11222-31.

72. Wang A, Jiang H. Palladium-catalyzed direct oxidation of alkenes with molecular oxygen: general and practical methods for the preparation of 1,2-diols, aldehydes, and ketones. J Org Chem. 2010;75:2321-6.

73. Reddy CR, Rao NN, Srikanth B. Total synthesis of a diarylheptanoid, rhoiptelol b. Eur J Org Chem. 2010;2010:345-51.
74. Lin D, Yi Y-J, Xiao M-W, Chen J, Ye J, Hu A-X, Lian W-W, Liu A-L, Du $\mathrm{G}-\mathrm{H}$. Design, synthesis and biological evaluation of honokiol derivatives as influenza neuraminidase inhibitors. J Asian Nat Prod Res. 2019;21:1052-67.

75. Chen S, Zeng G, LiY, He B, Liu R, Zhang S. Epoxide ring-opening reaction promoted by ionic liquid reactivity: interplay of experimental and theoretical studies. Catal Sci Technol. 2019;9:5567-71.

76. Brunelli NA, Long W, Venkatasubbaiah K, Jones CW. Catalytic regioselective epoxide ring opening with phenol using homogeneous and supported analogues of dimethylaminopyridine. Top Catal. 2012;55:432-8.

77. Telvekar VN, Patel DJ, Mishra SJ. Oxidative cleavage of epoxides using aqueous sodium paraperiodate. Synth Commun. 2008;39:311-5.

78. Binder CM, Dixon DD, Almaraz E, Tius MA, Singaram B. A simple procedure for $\mathrm{c}-\mathrm{c}$ bond cleavage of aromatic and aliphatic epoxides with aqueous sodium periodate under ambient conditions. Tetrahedron Lett. 2008;49:2764-7.

79. Lin D, Wang L, Yan Z, Ye J, Hu A, Liao H, Liu J, Peng J. Semi-synthesis, structural modification and biological evaluation of 5-arylbenzofuran neolignans. RSC Adv. 2018;8:34331-42.

80. Gieuw MH, Ke Z, Yeung YY. Lewis base-promoted ring-opening 1,3-dioxygenation of unactivated cyclopropanes using a hypervalent iodine reagent. Angew Chem Int Ed Engl. 2018:57:3782-6.

81. Khan FA, Hussain MA. Total synthesis of $( \pm)$-cassumunins a-c and curcumin analogues. Synthesis. 2020;52:1561-75.

82. Mitsudome T, Umetani T, Nosaka N, Mori K, Mizugaki T, Ebitani K, Kaneda K. Convenient and efficient Pd-catalyzed regioselective oxyfunctionalization of terminal olefins by using molecular oxygen as sole reoxidant. Angew Chem Int Ed Engl. 2006;45:481-5.

83. Roshchin Al, Kel'chevski SM, Bumagin NA. Synthesis of benzofurans via $\mathrm{Pd} 2+$-catalyzed oxidative cyclization of 2-allylphenols. J Organomet Chem. 1998:560:163-7.

84. Coulombel L, Duñach E. Triflic acid-catalysed cyclisation of unsaturated alcohols. Green Chem. 2004;6:499-501.

85. Lin D, Yan Z, Chen A, Ye J, Hu A, Liu J, Peng J, Wu X. Anti-proliferative activity and structure-activity relationship of honokiol derivatives. Bioorg Med Chem. 2019;27:3729-34.

86. Qunshan D, Yan Z, Zhenhua S, Chuanjun S, Junbiao C. Synthesis of a regioisomer of $\beta$-lapachone and analogs as potent antitumor agents. Helv Chim Acta. 2015;98:128-34.

87. Yagunov SE, Khol'shin SV, Kandalintseva NV, Prosenko AE. Synthesis and antioxidant activity of 5-hydroxycoumarans, 6-hydroxychromanes and sulfur-containing derivatives on their base. Russ Chem Bull. 2013:62:1395-400.

88. Vemula SR, Kumar D, Cook GR. Palladium-catalyzed allylic amidation with N-heterocycles via sp3 C-H oxidation. ACS Catal. 2016;6:5295-301.

89. Pattillo CC, Strambeanu II, Calleja P, Vermeulen NA, Mizuno T, White MC Aerobic linear allylic C-H amination: overcoming benzoquinone inhibition. J Am Chem Soc. 2016;138:1265-72.

90. Ma R, White MC. C-H to C-N cross-coupling of sulfonamides with olefins. J Am Chem Soc. 2018;140:3202-5.

91. Liu G, Yin G, Wu L. Palladium-catalyzed intermolecular aerobic oxidative amination of terminal alkenes: efficient synthesis of linear allylamine derivatives. Angew Chem. 2008:120:4811-4.

92. Burman JS, Harris RJ, Farr CMB, Bacsa J, Blakey SB. Rh(III) and Ir(III)Cp* complexes provide complementary regioselectivity profiles in intermolecular allylic C-H amidation reactions. ACS Catal. 2019;9:5474-9.

93. Knecht T, Mondal S, Ye JH, Das M, Glorius F. Intermolecular, branchselective, and redox-neutral Cp*Ir(III)-catalyzed allylic $\mathrm{C}-\mathrm{H}$ amidation. Angew Chem Int Ed Engl. 2019;58:7117-21.

94. Lei H, Rovis T. Ir-catalyzed intermolecular branch-selective allylic C-H amidation of unactivated terminal olefins. J Am Chem Soc. 2019;141:2268-73.

95. Kazerouni AM, Nelson TAF, Chen SW, Sharp KR, Blakey SB. Regioselective Cp*Ir(III)-catalyzed allylic C-H sulfamidation of allylbenzene derivatives. J Org Chem. 2019;84:13179-85.

96. Pandey G, Laha R. Visible-light-catalyzed direct benzylic C(sp(3))-H amination reaction by cross-dehydrogenative coupling. Angew Chem Int Ed Engl. 2015:54:14875-9.

97. Sharma A, Hartwig JF. Enantioselective functionalization of allylic C-H bonds following a strategy of functionalization and diversification. J Am Chem Soc. 2013:135:17983-9. 
98. Hussain N, Frensch G, Zhang J, Walsh PJ. Chemo- and regioselective $\mathrm{C}(\mathrm{sp}(3))-\mathrm{H}$ arylation of unactivated allylarenes by deprotonative crosscoupling. Angew Chem Int Ed Engl. 2014;53:3693-7.

99. Lerchen A, Knecht T, Koy M, Ernst JB, Bergander K, Daniliuc CG, Glorius F. Non-directed cross-dehydrogenative (hetero)arylation of allylic $\mathrm{C}(\mathrm{sp} 3)-\mathrm{H}$ bonds enabled by C-H Activation. Angew Chem Int Ed Engl. 2018:57:15248-52.

100. Wang PS, Lin HC, Zhou XL, Gong LZ. Palladium(II)/Lewis acid synergistically catalyzed allylic C-H olefination. Org Lett. 2014;16:3332-5.

101. Brucelle F, Renaud P. Synthesis of a leucomitosane via a diastereoselective radical cascade. J Org Chem. 2013;78:6245-52.

102. Li LL, Tao ZL, Han ZY, Gong LZ. Double chiral induction enables a stereoselective carbonyl allylation with simple alkenes under the sequential catalysis of palladium complex and chiral phosphoric acid. Org Lett. 2017; 19:102-5.

103. Tao ZL, Li XH, Han ZY, Gong LZ. Diastereoselective carbonyl allylation with simple olefins enabled by palladium complex-catalyzed $\mathrm{C}-\mathrm{H}$ oxidative borylation. J Am Chem Soc. 2015;137:4054-7.

104. Hemelaere R, Carreaux F, Carboni B. Cross-metathesis/isomerization/ allylboration sequence for a diastereoselective synthesis of antihomoallylic alcohols from allylbenzene derivatives and aldehydes. Chemistry (Easton). 2014;20:14518-23.

105. Schwarz JL, Schafers F, Tlahuext-Aca A, Luckemeier L, Glorius F. Diastereoselective allylation of aldehydes by dual photoredox and chromium catalysis. J Am Chem Soc. 2018;140:12705-9.

106. Jalab M, Critchley ME, Taylor CM, Lawrence CL, Smith RB. 1,8-Substituted anthraquinones, anthrones and bianthrones as potential nonazole leads against fungal infections. Bioorg Chem. 2019;91: 103151.

107. Goto H, Terao Y, Akai S. Synthesis of various kinds of isoflavones, isoflavanes, and biphenylketones and their 1,1-diphenyl-2-picrylhydrazyl radical-scavenging activities. Chem Pharm Bull (Tokyo). 2009:54:346-60.

108. Abdo NYM, Samir EM, Mohareb RM. Synthesis and evaluation of novel $4 \mathrm{H}$-pyrazole and thiophene derivatives derived from chalcone as potential anti-proliferative agents, Pim-1 kinase inhibitors, and PAINS. J Heterocycl Chem. 2020;57:1993-2009.

109. Saito Y, Goto M, Nakagawa-Goto K. Total synthesis of antiproliferative parvifloron F. Org Lett. 2018;20:628-31.

110. Gribble GW, Leese RM, Evans BE. Reactions of sodium borohydride in acidic media, iv. Reduction of diarylmethanols and triarylmethanols in trifluoroacetic acid. Cheminform. 1977:8:172-6.

111. Fonovic UP, Knez D, Hrast M, Zidar N, Proj M, Gobec S, Kos J. Structureactivity relationships of triazole-benzodioxine inhibitors of cathepsin X. Eur J Med Chem. 2020;193: 112218.

112. Mikami S, Sasaki S, Asano Y, Ujikawa O, Fukumoto S, Nakashima K, Oki H, Kamiguchi N, Imada H, Iwashita $\mathrm{H}$, et al. Discovery of an orally bioavailable, brain-penetrating, in vivo active phosphodiesterase 2a inhibitor lead series for the treatment of cognitive disorders. J Med Chem. 2017;60:7658-76.

113. Jiang L, Yin R, Wang X, Dai J, Li J, Jiang T, Yu R. Design and synthesis of neolamellarin a derivatives targeting heat shock protein 90. Eur J Med Chem. 2017;135:24-33.

114. Zhu X, Zhou X, Zhang W. One-pot reductive amination of araldehydes by aniline using borohydride with $\mathrm{CeCl}_{3} \cdot 7 \mathrm{H}_{2} \mathrm{O}$ as catalyst. J Chem Res. 2015;39:390-3.

115. Monaldi D, Rotili D, Lancelot J, Marek M, Wossner N, Lucidi A, Tomaselli D, Ramos-Morales E, Romier C, Pierce RJ, et al. Structure-reactivity relationships on substrates and inhibitors of the lysine deacylase sirtuin 2 from schistosoma mansoni (smsirt2). J Med Chem. 2019;62:8733-59.

116. Randino R, Cini E, D'Ursi AM, Novellino E, Rodriquez M. Facile BaeyerVilliger oxidation of cyclic ketones: conventional versus microwaveassisted approach. Tetrahedron Lett. 2015;56:5723-6.

117. Kumar N, Sharma CS, Ranawat MS, Singh HP, Chauhan LS, Dashora N. Synthesis, analgesic and anti-inflammatory activities of novel mannich bases of benzimidazoles. J Pharm Invest. 2014;45:65-71.

118. Lu LP, Suo FZ, Feng YL, Song LL, Li Y, Li YJ, Wang KT. Synthesis and biological evaluation of vanadium complexes as novel anti-tumor agents. Eur J Med Chem. 2019;176:1-10.

119. Hussain MK, Ansari MI, Yadav N, Gupta PK, Gupta AK, Saxena R, Fatima I, Manohar M, Kushwaha P, Khedgikar V, et al. Design and synthesis of ERa/ERß selective coumarin and chromene derivatives as potential anti-breast cancer and anti-osteoporotic agents. RSC Adv. 2014;4:8828-45.

120. Ducki S, Rennison D, Woo M, Kendall A, Chabert JF, McGown AT, Lawrence NJ. Combretastatin-like chalcones as inhibitors of microtubule polymerization. Part 1: synthesis and biological evaluation of antivascular activity. Bioorg Med Chem. 2009;17:7698-710.

121. Huang JK, Shia KS. Development of a cross-conjugated vinylogous [4+2] anionic annulation and application to the total synthesis of natural antibiotic (+/-)-ABX. Angew Chem Int Ed Engl. 2020;59:6540-5.

122. Pan G-F, Zhu X-Q, Guo R-L, Gao Y-R, Wang Y-Q. Synthesis of enones and enals via dehydrogenation of saturated ketones and aldehydes. Adv Synth Catal. 2018;360:4774-83.

123. Ferreira JRM, Nunes da Silva R, Rocha J, Silva AMS, Guieu S. 1,2,4-Triphenylpyrroles: synthesis, structure and luminescence properties. Synlett. 2020;31:632-4.

124. Gupta RA, Kaskhedikar SG. Synthesis, antitubercular activity, and QSAR analysis of substituted nitroaryl analogs: chalcone, pyrazole, isoxazole, and pyrimidines. Med Chem Res. 2012;22:3863-80.

125. Xu Z, Guo J, Yang Y, Zhang M, Ba M, Li Z, Cao Y, He R, Yu M, Zhou H, et al. 2,4,5-Trisubstituted thiazole derivatives as HIV-1 NNRTIs effective on both wild-type and mutant HIV-1 reverse transcriptase: optimization of the substitution of positions 4 and 5. Eur J Med Chem. 2016:123:309-16.

126. Evans RW, Zbieg JR, Zhu S, Li W, MacMillan DW. Simple catalytic mechanism for the direct coupling of alpha-carbonyls with functionalized amines: a one-step synthesis of Plavix. J Am Chem Soc. 2013;135:16074-7.

127. Jiang Q, Xu B, Zhao A, Jia J, Liu T, Guo C. Transition-metal-free oxidative alpha-C-H amination of ketones via a radical mechanism: mild synthesis of alpha-amino ketones. J Org Chem. 2014;79:8750-6.

128. Liang YF, Wu K, Song S, Li X, Huang X, Jiao N. 12- or NBS-catalyzed highly efficient alpha-hydroxylation of ketones with dimethyl sulfoxide. Org Lett. 2015;17:876-9.

129. Li H-L, An X-L, Ge L-S, Luo X, Deng W-P. Catalytic a-hydroxylation of ketones under CuBr 2 or HBr/DMSO systems. Tetrahedron. 2015;71:3247-52.

130. Hamed OA, El-Qisairi A, Qaseer H, Hamed EM, Henry PM, Becker DP. Asymmetric a-hydroxy ketone synthesis by direct ketone oxidation using a bimetallic palladium(II) complex. Tetrahedron Lett. 2012;53:2699-701.

131. Huang X, Liang X, Yuan J, Ni Z, Zhou Y, Pan Y. Aerobic copper catalyzed a-oxyacylation of ketones with carboxylic acids. Org Chem Front. 2017:4:163-9.

132. Guo S, Yu JT, Dai Q, Yang H, Cheng J. The Bu4NI-catalyzed alfa-acyloxylation of ketones with benzylic alcohols. Chem Commun (Camb). 2014:50:6240-2.

133. Zhu C, Zhang Y, Zhao H, Huang S, Zhang M, Su W. Sodium iodidecatalyzed direct a-alkoxylation of ketones with alcoholsviaoxidation of a-iodo ketone intermediates. Adv Synth Catal. 2015;357:331-8.

134. Wong T, Narayanan S, Brown DP, Chen ZS. Synthesis and cytotoxicity studies of stilbene long-chain fatty acid conjugates. J Nat Prod. 2020;83:1563-70

135. Lu C, Guo Y, Li J, Yao M, Liao Q, Xie Z, Li X. Design, synthesis, and evaluation of resveratrol derivatives as Ass((1)-(4)(2)) aggregation inhibitors, antioxidants, and neuroprotective agents. Bioorg Med Chem Lett. 2012:22:7683-7.

136. Akcok I, Cagir A. Synthesis of stilbene-fused 2'-hydroxychalcones and flavanones. Bioorg Chem. 2010;38:139-43.

137. Floresta G, Cilibrizzi A, Abbate V, Spampinato A, Zagni C, Rescifina A. 3D-QSAR assisted identification of FABP4 inhibitors: an effective scaffold hopping analysis/QSAR evaluation. Bioorg Chem. 2019;84:276-84.

138. Kindt S, Wicht K, Heinrich MR. Thermally induced carbohydroxylation of styrenes with aryldiazonium salts. Angew Chem Int Ed Engl. 2016:55:8744-7.

139. Wang T, Hu Y, Zhang S. A novel and efficient method for the olefination of carbonyl compounds with Grignard reagents in the presence of diethyl phosphite. Org Biomol Chem. 2010;8:2312-5.

140. Fang Y, Xia W, Cheng B, Hua P, Zhou H, Gu Q, Xu J. Design, synthesis, and biological evaluation of compounds with a new scaffold as 
anti-neuroinflammatory agents for the treatment of Alzheimer's disease. Eur J Med Chem. 2018;149:129-38.

141. Thompson CM, Orellana MD, Lloyd SE, Wu W. Stereospecific synthesis of cis-stilbenes from benzaldehydes and phenylacetic acids via sequential Perkin condensation and decarboxylation. Tetrahedron Lett. 2016;57:4866-8

142. Li S-Y, Wang X-B, Kong L-Y. Design, synthesis and biological evaluation of imine resveratrol derivatives as multi-targeted agents against Alzheimer's disease. Eur J Med Chem. 2014:71:36-45.

143. Reinhardt CJ, Zhou EY, Jorgensen MD, Partipilo G, Chan J. A ratiometric acoustogenic probe for in vivo imaging of endogenous nitric oxide. J Am Chem Soc. 2018;140:1011-8.

144. Zhao Y, Cao Y, Chen H, Zhuang F, Wu C, Yoon G, Zhu W, Su Y, Zheng S, Liu Z, et al. Synthesis, biological evaluation, and molecular docking study of novel allyl-retrochalcones as a new class of protein tyrosine phosphatase 1B inhibitors. Bioorg Med Chem. 2019;27:963-77.

145. Liu J, Chen C, Wu F, Zhao L. Microwave-assisted synthesis and tyrosinase inhibitory activity of chalcone derivatives. Chem Biol Drug Des. 2013;82:39-47.

146. Wen P, Tie W, Wang L, Lee M-H, Li X-D. Ultrasonic synthesis of 4,4'-dihydroxychalcone and its photochemical properties. Mater Chem Phys. 2009;117:1-3

147. Takao K, Yamashita M, Yashiro A, Sugita Y. Synthesis and biological evaluation of 3-benzylidene-4-chromanone derivatives as free radical scavengers and a-glucosidase inhibitors. Chem Pharm Bull (Tokyo). 2016;64:1203-7.

148. Bin ZJIC. Synthesis of chalcone catalyzed by solid superbase. Ind Catal. 2008; 16:71-4

149. Rakesh S, Sakthidharan CP, Sarojadevi M, Sundararajan PR. Monomer self assembly and organo-gelation as a route to fabricate cyanate ester resins and their nanocomposites with carbon nanotubes. Eur Polym J. 2015;68:161-74

150. Manickam M, Pichaimani P, Arumugam H, Muthukaruppan A. Synthesis of nontoxic pyrazolidine-based benzoxazine-coated cotton fabric for oil-water separation. Ind Eng Chem Res. 2019:58:21419-30.

151. Karki R, Park C, Jun KY, Kadayat TM, Lee ES, Kwon Y. Synthesis and biological activity of 2,4-di-p-phenolyl-6-2-furanyl-pyridine as a potent topoisomerase II poison. Eur J Med Chem. 2015:90:360-78.

152. Gaur R, Pathania AS, Malik FA, Bhakuni RS, Verma RK. Synthesis of a series of novel dihydroartemisinin monomers and dimers containing chalcone as a linker and their anticancer activity. Eur J Med Chem. 2016:122:232-46.

153. Liu C, Achtenhagen M, Szostak M. Chemoselective ketone synthesis by the addition of organometallics to $\mathrm{N}$-acylazetidines. Org Lett. 2016;18:2375-8

154. Kumar A, Akula HK, Lakshman MK. Simple synthesis of amides and weinreb amides via use of pph3 or polymer-supported pph3 and iodine. Eur J Org Chem. 2010. https://doi.org/10.1002/ejoc.200901420.

155. Crawford JJ, Henderson KW, Kerr WJ. Direct and efficient one-pot preparation of ketones from aldehydes using $\mathrm{N}$-tert-butylphenylsulfinimidoyl chloride. Org Lett. 2006:8:5073-6.

156. Cui Y, Li Y, Huang N, Xiong Y, Cao R, Meng L, Liu J, Feng Z. Structure based modification of chalcone analogue activates Nrf2 in the human retinal pigment epithelial cell line ARPE-19. Free Radic Biol Med. 2020;148:52-9.

157. Firouzabadi H, Karimi B, Abbassi M. Efficient solvent-free oxidation of benzylic and aromatic allylic alcohols and biaryl acyloins by manganese dioxide and barium manganate. J Chem Res. 1999. https://doi.org/10. 1039/a806954i.

158. Salehi P, Firouzabadi H, Farrokhi A, Gholizadeh M. Solvent-free oxidations of alcohols, oximes, aldehydes and cyclic acetals by pyridinium chlorochromate. Synthesis. 2001;15:2273-6.

159. Nishimura T, Onoue T, Ohe K, Uemura S. Palladium(II)-catalyzed oxidation of alcohols to aldehydes and ketones by molecular oxygen. J Org Chem. 1999;64:6750-5.

160. Riemer D, Mandaviya B, Schilling W, Götz AC, Kühl T, Finger M, Das S, $\mathrm{CO}_{2}$-catalyzed oxidation of benzylic and allylic alcohols with DMSO. ACS Catal. 2018:8:3030-4.

161. Jagtap PR, Cisarova I, Jahn U. Bioinspired total synthesis of tetrahydrofuran lignans by tandem nucleophilic addition/redox isomerization/ oxidative coupling and cycloetherification reactions as key steps. Org Biomol Chem. 2018;16:750-5.

162. Shoola CO, DelMastro T, Wu R, Sowa JR. Asymmetric transfer hydrogenation of secondary allylic alcohols. Eur J Org Chem. 2015;2015:1670-3.

163. Ibrahim JJ, Reddy CB, Zhang S, Yang Y. Ligand-free $\mathrm{FeCl}_{2}$-catalyzed a-alkylation of ketones with alcohols. Asian J Org Chem. 2019;8:1858-61.

164. Monserrat J-P, Tiwari KN, Quentin L, Pigeon P, Jaouen G, Vessières A, Chabot GG, Hillard EA. Ferrocenyl flavonoid-induced morphological modifications of endothelial cells and cytotoxicity against B16 murine melanoma cells. J Organomet Chem. 2013;734:78-85.

165. Gutam M, Mokenapelli S, Yerrabelli JR, Banerjee S, Roy P, Chitneni PR. Synthesis and cytotoxicity of novel (E)-2-phenylchroman-4-one-O-((1substituted-1H-1,2,3-triazol-4-yl)methyl) oxime derivatives. Synth Commun. 2020;50:1883-91.

166. Imran S, Taha M, Ismail NH, Kashif SM, Rahim F, Jamil W, Wahab H, Khan KM. Synthesis, in vitro and docking studies of new flavone ethers as alpha-glucosidase inhibitors. Chem Biol Drug Des. 2016:87:361-73.

167. Nayak BV, Ciftci-Yabanoglu S, Bhakat S, Timiri AK, Sinha BN, Ucar G, Soliman ME, Jayaprakash V. Monoamine oxidase inhibitory activity of 2-aryl-4H-chromen-4-ones. Bioorg Chem. 2015;58:72-80.

168. Ramesh P, Reddy CS, Suresh BK, Reddy PM, Srinivasa RV, Parthasarathy T. Synthesis, characterization and molecular docking studies of novel 2-amino 3-cyano pyrano[2,3H]chrysin derivatives as potential antimicrobial agents. Med Chem Res. 2015;24:3696-709.

169. Miyake H, Takizawa E, Sasaki M. Syntheses of flavones via the iodinemediated oxidative cyclization of 1,3-diphenylprop-2-en-1-ones. Bull Chem Soc Jpn. 2003;76:835-6.

170. Patil AM, Kamble DA, Lokhande PD. lodine-mediated direct synthesis of 3-iodoflavones. Synth Commun. 2018:48:1299-307.

171. Lahyani A, Trabelsi M. Ultrasonic-assisted synthesis of flavones by oxidative cyclization of 2'-hydroxychalcones using iodine monochloride. Ultrason Sonochem. 2016;31:626-30.

172. Kulkarni P, Kondhare D, Varala R, Zubaidha P. Cyclization of 2'-hydroxychalcones to flavones using ammonium iodide as an iodine source: an eco-friendly approach. J Serb Chem Soc. 2013;78:909-16.

173. Vimal M, Pathak U, Halve AK. Water-mediated phosphorylative cyclodehydrogenation: an efficient preparation of flavones and flavanones. Synth Commun. 2019;1-10.

174. Yamasaki K, Hishiki R, Kato E, Kawabata J. Study of kaempferol glycoside as an insulin mimic reveals glycon to be the key active structure. ACS Med Chem Lett. 2011:2:17-21.

175. Mughal EU, Sadiq A, Ashraf J, Zafar MN, Sumrra SH, Tariq R, Mumtaz A, Javid A, Khan BA, Ali A, et al. Flavonols and 4-thioflavonols as potential acetylcholinesterase and butyrylcholinesterase inhibitors: synthesis, structure-activity relationship and molecular docking studies. Bioorg Chem. 2019;91: 103124.

176. Borsari C, Jimenez-Anton MD, Eick J, Bifeld E, Torrado JJ, Olias-Molero Al, Corral MJ, Santarem N, Baptista C, Severi L, et al. Discovery of a benzothiophene-flavonol halting miltefosine and antimonial drug resistance in Leishmania parasites through the application of medicinal chemistry, screening and genomics. Eur J Med Chem. 2019;183: 111676.

177. Shen X, Zhou Q, Xiong W, Pu W, Zhang W, Zhang G, Wang C. Synthesis of 5-subsituted flavonols via the Algar-Flynn-Oyamada (AFO) reaction: the mechanistic implication. Tetrahedron. 2017;73:4822-9.

178. Mughal EU, Sadiq A, Murtaza S, Rafique H, Zafar MN, RiazT, Khan BA, Hameed A, Khan KM. Synthesis, structure-activity relationship and molecular docking of 3-oxoaurones and 3-thioaurones as acetylcholinesterase and butyrylcholinesterase inhibitors. Bioorg Med Chem. 2017:25:100-6

179. Giri RR, Lad HB, Bhila VG, Patel CV, Brahmbhatt DI. Modified pyridinesubstituted coumarins: a new class of antimicrobial and antitubercular agents. Synth Commun. 2014;45:363-75.

180. Auwers KV. Formation of flavonols from benzylidenecoumaranones. Ber Dtsch Chem Ges. 1916;49:809-18.

181. Shaik JB, Yeggoni DP, Kandrakonda YR, Penumala M, Zinka RB, Kotapati KV, Darla MM, Ampasala DR, Subramanyam R, Amooru DG. Synthesis and biological evaluation of flavone-8-acrylamide derivatives as potential multi-target-directed anti Alzheimer agents and investigation of binding mechanism with acetylcholinesterase. Bioorg Chem. 2019;88: 102960. 
182. Ohoka N, Tsuji G, Shoda T, Fujisato T, Kurihara M, Demizu Y, Naito M. Development of small molecule chimeras that recruit AhR E3 Ligase to target proteins. ACS Chem Biol. 2019;14:2822-32.

183. Nussbaumer P, Lehr P, Billich A. 2-Substituted 4-(thio)chromenone 6-o-sulfamates: potent inhibitors of human steroid sulfatase. J Med Chem. 2002;45:4310-20.

184. Pathak VN, Gupta R, Varshney B. A "one pot" synthesis of 2-aryl4h-1-benzopyran-4-ones under coupled microwave phase transfer catalysis (PTC) and ultrasonic irradiation PTC. J Heterocycl Chem. 2008:45:589-92

185. Seijas JA, Pilar Vázquez-Tato M, Carballido-Reboredo R. Solvent-free synthesis of functionalized flavones under microwave irradiation. J Org Chem. 2005;70:2855-8.

186. Maiti G, Karmakar R, Bhattacharya RN, Kayal U. A novel one pot route to flavones under dual catalysis, an organo- and a Lewis acid catalyst. Tetrahedron Lett. 2011;52:5610-2.

187. Kondhare DD, Gyananath G, Tamboli Y, Kumbhar SS, Choudhari PB, Bhatia MS, Zubaidha PK. An efficient synthesis of flavanones and their docking studies with aldose reductase. Med Chem Res. 2017;26:987-98.

188. Kavala V, Lin C, Kuo C-W, Fang H, Yao C-F. lodine catalyzed one-pot synthesis of flavanone and tetrahydropyrimidine derivatives via Mannich type reaction. Tetrahedron. 2012;68:1321-9.

189. Kwon HB, Park C, Jeon KH, Lee E, Park SE, Jun KY, Kadayat TM, Thapa $P$, Karki R, Na Y, et al. A series of novel terpyridine-skeleton molecule derivants inhibit tumor growth and metastasis by targeting topoisomerases. J Med Chem. 2015;58:1100-22.

190. Yoshida M, Fujino Y, Saito K, Doi T. Regioselective synthesis of flavone derivatives via DMAP-catalyzed cyclization of o-alkynoylphenols. Tetrahedron. 2011;67:9993-7.

191. Saito K, Yoshida M, Doi T. An efficient synthesis of aurone derivatives by the tributylphosphine-catalyzed regioselective cyclization of o-alkynoylphenols. Chem Lett. 2015;44:141-3.

192. Taylor C, Bolshan Y. Metal-free methodology for the preparation of sterically hindered alkynoylphenols and its application to the synthesis of flavones and aurones. Tetrahedron Lett. 2015;56:4392-6.

193. Yoshida M, Fujino Y, Deoi T. Synthesis of gamma-benzopyranone by $\mathrm{TfOH}$-promoted regioselective cyclization of o-alkynoylphenols. Org Lett. 2011;13:4526-9.

194. Zhai D, Chen L, Jia M, Ma S. One pot synthesis of $\gamma$-benzopyranones via iron-catalyzed aerobic oxidation and subsequent 4-dimethylaminopyridine catalyzed 6-endo cyclization. Adv Synth Catal. 2018;360:153-60.

195. Zhang S, Wan C, Wang Q, Zhang B, Gao L, Zha Z, Wang Z. Synthesis of chromones through LiOtBu/air-mediated oxidation and regioselective cyclization ofo-hydroxyphenyl propargyl carbinols. Eur J Org Chem. 2013;2013:2080-3.

196. Lu TM, Ko HH, Ng LT, Hsieh YP. Free-radical-scavenging, antityrosinase, and cellular melanogenesis inhibitory activitiesofsynthetic isoflavones. Chem Biodivers. 2015;12:963-79.

197. Yadav SK. Process for the preparation of chromones, isoflavones and homoisoflavones using vilsmeier reagent generated from phthaloyl dichloride and DMF. Int J Org Chem. 2014;04:236-46.

198. Kshatriya RB, Shaikh Yl, Nazeruddin GM. Microwave assisted synthesis of isoflavones. J Chem Pharm Res. 2015:7:543-8.

199. Singh A, Bimal D, Kumar R, Maikhuri VK, Thirumal M, Senapati NN, Prasad AK. Synthesis and antitubercular activity evaluation of 4-furanocoumarins and 3-furano-chromones. Synth Commun. 2018;48:2339-46.

200. Liu L, Wang Q, Zhang Z, Zhang Q, Du Z, Xue D, Wang T. An efficient strategy to syntheses of isoflavones. Mol Divers. 2014;18:777-85.

201. Huang DM, Li HJ, Wang JH, Wu YC. Asymmetric total synthesis of talienbisflavan A. Org Biomol Chem. 2018;16:585-92.

202. Wagner TA, Liu J, Stipanovic RD, Puckhaber LS, Bell AA. Hemigossypol, a constituent in developing glanded cottonseed (Gossypium hirsutum). J Agric Food Chem. 2012;60:2594-8.

203. Li L, Liu Y, Wang Q. Regioselective oxidative dehydrogenation under nonenzymatic conditions: a synthetic route to gossypol. Eur J Org Chem. 2013:2013:8014-21.

204. Fryszkowska A, Devine PN. Biocatalysis in drug discovery and development. Curr Opin Chem Biol. 2020;55:151-60.

205. Trosset JY, Carbonell P. Synthetic biology for pharmaceutical drug discovery. Drug Des Devel Ther. 2015;9:6285-302.

\section{Publisher's Note}

Springer Nature remains neutral with regard to jurisdictional claims in published maps and institutional affiliations.

\section{Submit your manuscript to a SpringerOpen ${ }^{\circ}$ journal and benefit from:}

- Convenient online submission

- Rigorous peer review

- Open access: articles freely available online

- High visibility within the field

- Retaining the copyright to your article

Submit your next manuscript at $\boldsymbol{\nabla}$ springeropen.com 